\title{
Modelling Internet of Things (IOT) driven global sustainability in multi-tier agri-food supply chain under natural epidemic outbreaks
}

\section{Sanjeev Yadav}

Research Scholar, Department of Mechanical Engineering, National Institute of Technology, Kurukshetra136119, Haryana, India

Dr. Sunil Luthra ( $\nabla$ sunilluthra1977@gmail.com ) Assistant Professor, Department of Mechanical Engineering, Ch. Ranbir Singh State Institute of Engineering and Technology, Jhajjar-124103, Haryana, India https://orcid.org/0000-0001-7571-1331

\section{Dixit Garg}

Professor, Department of Mechanical Engineering, National Institute of Technology, Kurukshetra136119, Haryana, India

\section{Method Article}

Keywords: Agri-Food Supply Chain (AFSC), COVID-19, Global Sustainability. Internet of Things (IoT), Food security, Multi-tier, Supply Chain Disruption

Posted Date: October 2nd, 2020

DOl: https://doi.org/10.21203/rs.3.rs-84820/v1

License: (c) (1) This work is licensed under a Creative Commons Attribution 4.0 International License. Read Full License

Version of Record: A version of this preprint was published at Environmental Science and Pollution Research on January 3rd, 2021. See the published version at https://doi.org/10.1007/s11356-020-116761. 


\section{Modelling Internet of Things (IoT) driven global sustainability in} multi-tier agri-food supply chain under natural epidemic

\section{outbreaks}

\author{
Sanjeev Yadav \\ Research Scholar, Department of Mechanical Engineering, \\ National Institute of Technology, Kurukshetra-136119, Haryana, India \\ E-mail: ysanjeev949@gmail.com
}

\section{Dr. Sunil Luthra*}

Assistant Professor, Department of Mechanical Engineering,

Ch. Ranbir Singh State Institute of Engineering and Technology, Jhajjar-124103, Haryana, India

E-mail: sunilluthra1977@gmail.com

Phone-91-9466594853

\section{Dr. Dixit Garg}

Professor, Department of Mechanical Engineering, National Institute of Technology, Kurukshetra-136119, Haryana, India

E-mail: dixitgarg@yahoo.co.in

*Corresponding author 


\section{Modelling Internet of Things (IoT) driven global sustainability in}

multi-tier agri-food supply chain under natural epidemic outbreaks

Abstract: The resilience of Agri-Food Supply Chain (AFSC) due to recent epidemics outbreak (COVID-19, SARS-CoV-2) has not been matching with, globalisation of AFSC, and complicated networking system of AFSC and thus poses huge global sustainable issues. Thus, the aim of this research is the modelling of the sustainable AFSC secure mechanism managed through different emerging application of Internet of Things (IoT) technology (Blockchain, Robotics, Big data analysis and Cloud computing). Competitive Supply Chain Management (SCM) needs cautious incorporation of multi- tiers suppliers, specifically during dealing with globalised sustainability issues. Firms have been advancing towards their multi suppliers for driving social and environments and economical practices. This paper also studies the interrelationship and their cause and effect magnitude among various enablers contributing to IoT based food secure model. The methodology used in the paper is Interpretative Structural Modelling (ISM) for establishing interrelationship among the variables and Fuzzy-Decision-Making Trial and Evaluation Laboratory (F-DEMATEL) to provide the magnitude of the cause-effect strength of the hierarchical framework. Finally, this paper has limitation of taking only factors related to food security system by considering present natural epidemics of COVID-19. In future, other dimensions of AFSC may be considered based on COVID-19 epidemics effect on AFSC.

Keywords: Agri-Food Supply Chain (AFSC); COVID-19; Global Sustainability; Internet of Things (IoT); Food security; Multi-tier; Supply Chain Disruption.

\section{Introduction}

By the increased growth of global SCM, disruptions are continuously taking place in AgriFood Supply Chain (AFSC) (Kamalahmadi and Parast, 2016; Hosseini et al., 2019). AFSC risks are complex and may be classified into functional and disrupting risks (Choi et al., 2019; Xu et al., 2020). The functional risks are connected by daily disorders in the AFSC functions like lead time of agri products production, processing and demand's fluctuating, the disrupting risks associated as low-frequency-highly-impacting actions (Kinra et al., 2019; Ivanov, 2020). Disrupting actions (COVID 19) have instant impacts on AFSC and its 
networking system, results shortage of retailers, distribution centres and transportation facilities. Consequentially, insufficient agri-food products shortages and delaying of services propagated towards AFSC's downstream, leads to the rippling effect and competitive disadvantages in the form of performance degradation (Dolgui et al., 2018; Dolgui et al., 2020; Li and Zobel, 2020). Araz et al. (2020) noticed that the COVID-19 outbreak "breaking many global supply chains" as the World Health Organisation (WHO) declared COVID-19 as pandemic. In this natural epidemics condition, it is prerequisite to considered multi-tier sustainable issues of AFSC.

Although, industries interrelationships in AFSC are mostly dynamic, globalised sustainable issues related to certification provided by different globalised standards, and traceability demanding for the interaction of Focal Firm (FF) across different countries by integrating with their sub-suppliers in a multi-tier system (Overstreet et al., 2013). As per the report of economic and social department (United Nations), the world wide population may increase to 8.5 billion by 2030 . So, globalised agri-production must be increase for matching the consumer's demands, which may increase the global sustainability issues. For this sustainable initiatives have been taken like "Paris Agreement" on reducing Green House Gases (GHG) emissions during various agri practices and Common Agriculture Policies (CAP) for improving AFSC practices as a multi-tier system (Achabou et al., 2017).

Multi-tier based sustainability of AFSC may help in reduction of loses at different phases with minimising of deterioration of the agri-food qualities, and thus contributed AFSC sustainability (Clarke and Boersma, 2017). Without considering sustainable factors, agri-food secure system may not be achieved. Thus, the term sustainable based agri- food secure system is getting much more focused from area of research, academics and policy making. Sustainability approach in AFSC may provide sufficient agri-food by adopting sustainable actions of AFSC by effective designing of SCM (Allaoui et al., 2018). The traditional AFSC in India is facing different problems in procuring, storing and distributing, agri-food losses and deteriorations (Misangyi et al., 2016). To overcome above problems, IoT based SCM must be employed for ensuring transparent, traceable and accountable system at different levels of AFSC (Kauppi and Hannibal, 2017). This paper explores different IoT technologies like Blockchain, Artificial Intelligence (AI), Robotics, RFID, etc. (Hartmann and Moeller, 2014; Aboah et al., 2019). The following research objectives may be set:

- Identification of the factors in driving IoT driven multi-tier sustainability for AFSC; 
- To establish the interaction among identified enablers for IoT based sustainability for a food secure mechanism;

- To established a contextual interrelationship between the enablers by classifying into caused and influenced clusters; and

- Recommending managerial implications of the proposed research.

This research will also try to respond the given research questions:

- What may be needs of IoT driven multi-tier food security system in any natural epidemics (COVID19)?

In current scenario, tracking of processes in AFSC is critical by providing a basic idea of agri-product's past background, operational as well as processes throughout the SCM; however traditional AFSC has not been tackling this kind of tracking mechanism. Further, monitoring of food regulatory standards leads to standardisation in practices of food processing, packaging, distribution and retailing (Dev et al., 2020). Thus, there is a need of IoT driven food security system for ensuring sustainability at globalised level.

- What are the criterions for the selection of enablers in IoT driven multi-tier food security system for ensuring global sustainability?

Different enablers involves in the IoT driven multi-tier food security system based on the three decision model i.e. strategic (making long term planning), tactical (put strategies into action) and operational level practices (actual action implementation) (Busse et al., 2016). Thus, three decision based model have been opted for enabler identification to address the different issues related to IoT driven food security system to ensure global sustainability.

- What type of methodologies may be employed for establishing interrelationship between the enablers and analyse cause and effect extent?

In this paper, an integrated ISM-DEMATEL approach is helping in transforming the vague and unorganised structural into a systematic structure and establishment of interdependency between the enablers by formulating causal and influenced group clusters (Chauhan et al., 2018). Further, sensitivity analysis needs to be performed to check the result robustness.

- How this study can be employed in practical implications for managers and practitioners? 
ISM- DEMATEL based analysis of the identified enablers was used by managers in making their longer termed basis resilient strategies. This research has the capability to guide the managers in adoption the most feasible IoT based technologies in AFSC with economical based customer's satisfaction with new horizons of productivity (Wilhelm et al., 2016b).

Further, organisation of proposed research: Section 2 elaborates the Literature Review. Section 3 elaborates research methodology. Section 4 provides practical applications of this study with numerical illustration. Section 5 discussed findings with its implications. Finally, Section 6 contributes to conclusions with limitations and future scope of this research.

\section{Literature Review}

In the given sub-sections, literature work has been made for the identification of enablers and to identify research gaps.

\subsection{Requirement of Global Sustainability under COVID 19 Outbreak}

With respect to COVID 19, food industries have been noted that primary agri production may not be largely declined as most of the farmlands are way distant from urbanised. But, the pandemic may affect agri-harvesting, processing, logistics and distributing and thus, poses globalised issues of sustainability (Ben-Daya et al., 2019; Dun and Bradsteet, 2020). Thus, food organisations required to implement sustainable practices at different multitier stages related to processing, transporting, retailing, packing, handling, cold storage and loading.

Therefore, there is a need of IoT based system for communicating information of agri-food safety standards in an effective way to different suppliers of AFSC (Luvisi, 2016; Talavera et al., 2017). Further, in this global pandemic situation, there is a growth opportunities exist for the industries to provide quick response/online purchasing (e-commerce) or local/short SC based supplying the requirements of consumers and thus achieving sustainability (Farahani et al., 2020; Li and Zobel, 2020).

\subsection{Impact of IoT based Multi-tier System on Sustainable AFSC at Global Level}

Multi-tier configuration type and IoT based governance mechanisms are the key elements for sustainable development in Global AFSC. Global AFSC encompassed the IoT based involvement of multi-tier sustainable practices and initiatives driven by FF, ES (External Supports) provides by government and NGOs, Third Parties (TP) and some other stakeholders. Direct governing mechanisms needs FF to provide time and capital for effectively establishing the associations with multi-suppliers and indirect governing 
mechanisms depends on third parties standards and regulation without any direct influence of FF. This governance system provides diverse implications for sustainable outcomes in Global AFSC (Formentini and Taticchi, 2016; Zhu et al., 2017) as shown in Figure 1.

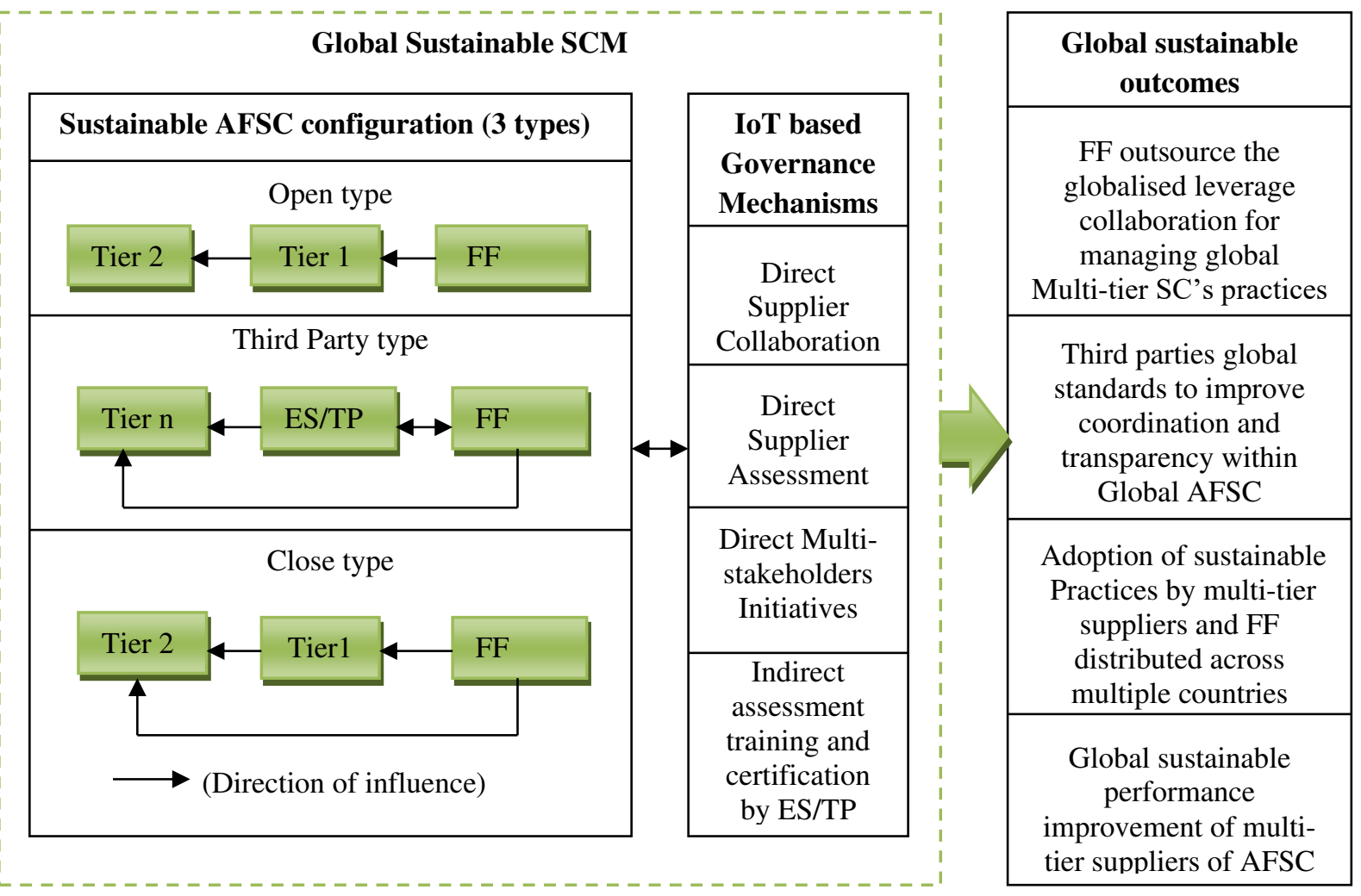

Figure 1: Research framework of Sustainable AFSC and Global AFSC

\subsection{Identification of Factors for IoT based Multi-tier Sustainable Food Security System}

Depending on literature survey, fourteen factors have been identified for developing IoT based sustainable multi-tier food security system in a natural disruption of AFSC. The research databases used in this research are Emerald (www.emeraldinsight.com), Taylor and Francis (https://taylorandfrancis.com), Elsevier (www.sciencedirect.com), Springer (www.springerlink.com), Wiley (www.wiley.com) and IEEE journals (Chadegani et al., 2013). The main searched criteria consisting of published articles ranging from year 2005 to 2020. Majority of the reviewed papers have been taken from the International Journal of Production Economics, Journal of Cleaner Production and International Journal of Production Research etc. The below given keyword's strings have been entered as in title:

1. ("Global agriculture food supply chain” OR "global value chain” OR "global supply chain management”) AND (“sustainable” OR "resilience” OR “disruptions”).

2. ("agri-supply chain management" OR "resilience supply chain management" OR "sustainable supply chain management") AND ("Internet of Things" OR "global"). 
3. ("IoT driven sustainable agri food supply chain management" OR "green supply chain "management" OR "global supply chain disruptions") AND ("modeling" OR "multi-tier" OR "governance" OR “configuration" OR "natural outbreak").

Thus, this provides first level all searched database ( $\mathrm{n}=150$ papers) having links between various scope of global sustainability, IoT based multi-tier system of AFSC and natural epidemics outbreak. The complete process of paper selection and exclusion is shown in Figure 2.

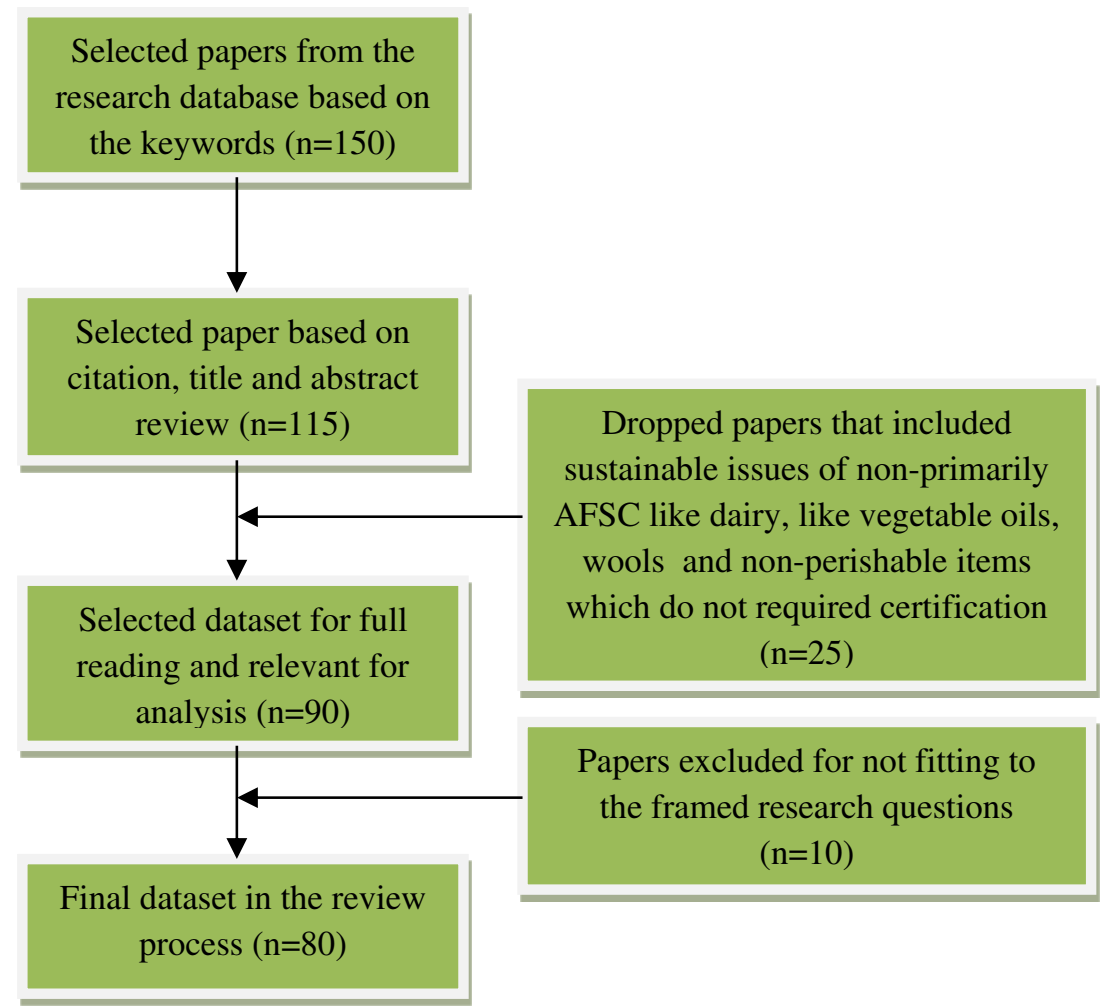

Figure 2: Article searching, selection and exclusion process

Brief description of the identified factors has been explained in Table 1.

Table 1: Identification of enablers for IoT based multi-tier sustainable food security system of AFSC

\begin{tabular}{|l|l|l|}
\hline \multicolumn{1}{|c|}{ Enablers } & \multicolumn{1}{c|}{ Brief description } & \multicolumn{1}{c|}{ References } \\
\hline $\begin{array}{l}\text { E-governance and } \\
\text { policy (C1) }\end{array}$ & $\begin{array}{l}\text { This provides effective controlling and tracking } \\
\text { of the sustainable AFSC practises by sharing } \\
\text { efforts of government organisation, NGOs, CAP, } \\
\text { food processing organisations and farmers by the } \\
\text { means of third party type multi-tier and indirect } \\
\text { governing mechanism. }\end{array}$ & \\
$\begin{array}{ll}\text { Armanda et al., 2017; } \\
2019\end{array}$ \\
\hline $\begin{array}{l}\text { Education and } \\
\text { training (C2) }\end{array}$ & $\begin{array}{l}\text { Technical training includes awareness of multi- } \\
\text { tier sub suppliers about IoT technology, food }\end{array}$ & $\begin{array}{l}\text { Sharma and Vrat, } \\
2018\end{array}$ \\
\hline
\end{tabular}




\begin{tabular}{|c|c|c|}
\hline & $\begin{array}{l}\text { regulation standards like Hazard Analysis and } \\
\text { Critical Control Point (HACCP), Good Hygiene } \\
\text { Practices (GHP),International Organisation for } \\
\text { Standardisation (ISO) for food product handling } \\
\text { by maintaining social distancing and farmer to } \\
\text { implement IoT based farming practices. }\end{array}$ & \\
\hline $\begin{array}{l}\text { Top management } \\
\text { support }(\mathrm{C} 3)\end{array}$ & $\begin{array}{l}\text { It insures funds, proper training, award/reward } \\
\text { sharing and awareness program about technical } \\
\text { (IoT technology) knowledge, food products } \\
\text { handling practices, effective information sharing. } \\
\text { It also provides PPE, gloves, mask for the } \\
\text { workers. Thus, it ingrates sustainable initiatives } \\
\text { to global SCM. }\end{array}$ & $\begin{array}{l}\text { Linton and Vakil, } \\
2014 \text {; Irani and } \\
\text { Sharif, 2016; Gupta } \\
\text { and Ivanov, } 2020\end{array}$ \\
\hline $\begin{array}{l}\text { IoT } \quad \text { based } \\
\text { infrastructure }(\mathrm{C} 4)\end{array}$ & $\begin{array}{l}\text { IoT based infrastructure is the availability and } \\
\text { collaboration of each IoT based technology } \\
\text { throughout the multi-tier AFSC. Different IoT } \\
\text { technologies such as RFID tags and readers, } \\
\text { Sensors, Blockchain, AI, BDA, Robotics, Cloud } \\
\text { computing and Zig bee etc. }\end{array}$ & $\begin{array}{l}\mathrm{Li} \text { et al., 2014; } \\
\text { Saberi et al., } 2019\end{array}$ \\
\hline $\begin{array}{l}\text { Setting of food } \\
\text { quality } \\
\text { (C5) }\end{array}$ & $\begin{array}{l}\text { Imposing the third parties' food regulation } \\
\text { standards by the means implementing various } \\
\text { standardised practices or information within the } \\
\text { food SC during the execution of various SC } \\
\text { activities. }\end{array}$ & $\begin{array}{l}\text { Fanzo, 2015; Ben- } \\
\text { Daya et al., } 2019\end{array}$ \\
\hline $\begin{array}{l}\text { Information } \\
\text { sharing (C6) }\end{array}$ & $\begin{array}{l}\text { Information sharing is prerequisite for } \\
\text { exchanging ideas between different sub suppliers } \\
\text { of multi-tier system. Further, information sharing } \\
\text { improves food product recycling by proper } \\
\text { information sharing between retailer, supplier } \\
\text { and consumers. }\end{array}$ & $\begin{array}{l}\text { Fuglie, 2016; Saberi } \\
\text { et al., } 2019\end{array}$ \\
\hline $\begin{array}{l}\text { Coordination and } \\
\text { collaboration (C7) }\end{array}$ & $\begin{array}{l}\text { Global standards based effective coordination } \\
\text { and collaboration between food regulation } \\
\text { authorities, food processing organisation, } \\
\text { supplier, warehouse and consumers supports the } \\
\text { identification of human and organisational risks } \\
\text { related to agri food safety and security to ensure } \\
\text { global sustainability. }\end{array}$ & $\begin{array}{l}\text { Luvisi, } 2016 \text {; } \\
\text { Nakandala et al., } \\
2017\end{array}$ \\
\hline $\begin{array}{l}\text { Quality control of } \\
\text { agri products }(\mathrm{C} 8)\end{array}$ & $\begin{array}{l}\text { It mainly depends on the 3D images of food } \\
\text { grains and packed product based on the IoT } \\
\text { based sensor technology 3D images of food } \\
\text { items with study of their pattern recognised the } \\
\text { quality control processes for better controlling of } \\
\text { quality of agri products. }\end{array}$ & $\begin{array}{l}\text { Bosona and } \\
\text { Gebresenbet, } 2013\end{array}$ \\
\hline $\begin{array}{l}\text { E-farm marketing } \\
\text { (C9) }\end{array}$ & $\begin{array}{l}\text { E farm marketing is the using of on-line portal } \\
\text { for connecting farmer/food processing } \\
\text { organisation to the big retailers connected to } \\
\text { focal firms across the different countries. } \\
\text { Improved information sharing based on RFID } \\
\text { tags/readers and barcodes technologies also lead } \\
\text { to E-farm marketing. }\end{array}$ & $\begin{array}{l}\text { Masiero, } \\
\text { 2015;Manavalan } \\
\text { and Jayakrishna, } \\
2019\end{array}$ \\
\hline
\end{tabular}




\begin{tabular}{|c|c|c|}
\hline $\begin{array}{l}\text { Route optimisation } \\
\text { (C10) }\end{array}$ & $\begin{array}{l}\text { It provides the optimum route to the consumers } \\
\text { by using cloud computational technology which } \\
\text { is for the optimisation of distributing network of } \\
\text { different countries. }\end{array}$ & $\begin{array}{l}\text { Validi et al., 2014; } \\
\text { Irani and Sharif, } \\
2016\end{array}$ \\
\hline $\begin{array}{l}\text { Simulating the } \\
\text { consumption } \\
\text { pattern }(\mathrm{C} 11)\end{array}$ & $\begin{array}{l}\text { It provides simulation based big data analysis for } \\
\text { matching the demand of consumers of globally } \\
\text { located. Thus, it may predict for the planning of } \\
\text { agri-food distribution to ensure agri-food } \\
\text { security and safety. }\end{array}$ & $\begin{array}{l}\text { Badami and } \\
\text { Ramankutty, 2015; } \\
\text { Vanderroost et al., } \\
2017\end{array}$ \\
\hline $\begin{array}{l}\text { Smart packaging } \\
\text { of agri products } \\
(\mathrm{C} 12)\end{array}$ & $\begin{array}{l}\text { It is AI based intelligent packing of agri } \\
\text { products, so that a best before date may be } \\
\text { decide to simulate the barcode with expiring date } \\
\text { of agri products by considering ambient, } \\
\text { environmental or climate condition and long } \\
\text { distributing chain of multi-tier system across } \\
\text { different countries. }\end{array}$ & $\begin{array}{l}\text { Ahmad and Mondal, } \\
\text { 2019; Saberi et al., } \\
2019\end{array}$ \\
\hline $\begin{array}{l}\text { Cold chain for } \\
\text { perishable } \\
\text { products }(\mathrm{C} 13)\end{array}$ & $\begin{array}{l}\text { Cold chain for perishable products is the } \\
\text { development of IoT interfaced refrigerant } \\
\text { facility. The refrigerant or cold chain intensity } \\
\text { may be adjusted depending on the type of global } \\
\text { climate in different countries, quantities of agri } \\
\text { products e.g. food grains or perishable } \\
\text { vegetables. }\end{array}$ & $\begin{array}{l}\text { Talavera et al., } \\
\text { 2017; Benis and } \\
\text { Ferrão, } 2018\end{array}$ \\
\hline $\begin{array}{l}\text { Sustainable based } \\
\text { competitive AFSC } \\
\text { (C14) }\end{array}$ & $\begin{array}{l}\text { This system focused on AFSC processes by safe } \\
\text { distributing, safe storage and reduction of food } \\
\text { loss during natural epidemic outbreak (COVID } \\
\text { 19) for ensuring competiveness with multi-tier } \\
\text { sustainability at global level across different } \\
\text { countries. }\end{array}$ & $\begin{array}{l}\text { Gupta and Ivanov, } \\
\text { 2020; Li and Zobel, } \\
\text { 2020; Gwynn-Jones } \\
\text { et al., } 2018\end{array}$ \\
\hline
\end{tabular}

\subsection{Research Gaps}

The following research gaps have been reported based upon the review of literature:

- In previous literature work, most of the work has focused only on the increasing agriproduction or agri based yield and less literature work has been done on minimisation of AFSC losses or agri food security issues like crop insurance, simulation of demand and smart contact etc. (Naik and Suresh, 2018).

- A few researches have supported the environmental, economical and social sustainable aspects at globalised level while reviewing the SC disruption (COVID 19) issues. There is a requirement of sustainable based quick processes transaction during the both tier 1 and lower tier by considering producing stage, procuring stage, transporting stage, warehouse and distributing stage to attain sustainable based multi-tier food secure system (Govindan, 
- Most of the previous literature has only given attention on the specific applications of a single IoT technology. But, in the developing of an IoT dependent sustainable agri-food secures structure; there is a requirement of integration among different IoT technologies. However, less literature has been supported for the integration of IoT technologies, which may interact on real time basis to develop a resilience and effective system for mitigating the disruption risks (Papadopoulos et al., 2017; Ivanov et al., 2019).

- Most of the previous work has only oriented in one direction, either worked as qualitatively or quantitatively approach. Only few studies have taken case studies along with numerical analysis of enablers with their individual effects on the entire system of AFSC for an IoT driven global sustainable AFSC's security system (Ho et al., 2015; Moazzam et al., 2018).

\section{Research Methodology}

The research methodology employed a two steps study as shown in Figure 3.

[Figure 3 about here]

For the evaluation of the factors for IoT based sustainability in AFSC. In the first phase, identification of enablers based on reviewed literature and expert's suggestions. By this procedure, fourteen important factors have been identified and verified by experts' suggestions. In the second phase, identified factors have been evaluated by using combined ISM and fuzzy DEMATEL. There are different techniques available such as ISM, Total ISM, DEMATEL and Analytical Hierarchical Process (AHP) for providing a structure based relationships of the enablers but could not provide the quantified view of the interrelationships (Dos Muchangos et al., 2015; Luthra et al., 2016; Chauhan et al., 2018). Hence, for the quantification of the inter-relationships for any sophisticated system, integrated ISMDEMATEL approach may be applied. But, standard DEMATEL technique has a drawback as it does not have capabilities for dealing with any uncertainty of real case (Kirkire and Rane, 2017). To avoid this drawback, there is a need of integrating DEMATEL with the fuzzy set theory proposed by Zadeh (1965).

\subsection{ISM Methodology}

ISM was initially introduced in 1970s by Warfield (1974). ISM may be adopted to establish the inter-relationships among the enablers by converting the unorganised system into a systemically organised system (Kapse et al., 2017; Chaple et al., 2018). 
Figure 3: Framework of the proposed research

ISM is commonly chosen among other modelling methods as it elaborates the type of interrelationships type between enablers (Luthra et al., 2016; Shen et al., 2016). The stepwise 
301

302

303

304

305

306

307

308

309

310

311

312

313

314

315

316

317

318

319

320

321

322

323

324

325

326

327

328

329

330

331

332

explanation of this methodology is given in research framework as shown Figure 3. ISM has different steps as explained below.

(1) Identification of the enablers. In the current research, enablers are connected to develop IoT based multi-tier sustainable food security system.

(2) Development the contextual inter-relationships between enablers given by the expert's suggestions.

(3) Constructing a SSIM. The advice of different experts has been utilised.

(4) Development of final reachable matrix. SSIM is utilised for the development of the initial reachable matrix; this matrix is then changed to final reachable matrix by finding out any transitivity links between the identified enablers.

(5) Formation of the partition levels based on final reachable matrix.

(6) Conducting the MICMAC analysis for the identified enablers.

(7) Constructing the digraph.

(8) Formation of the ISM model by removing transitivity links.

\subsection{FUzzy-DEMATEL}

DEMATEL approach was first introduced by the Geneva research centre. The DEMATEL is a numerical technique, which may be utilised for analysing the cause and effect strength between interrelated variables of a complicated system (Tzeng et al., 2007). DEMATEL technique established the relation between enablers by classifying them in causal and effects and thus, provides possible outcome based on an organised and systematic system (Lin, 2013; Wu, 2008; Hsu et al., 2013). Thus, Fuzzy based DEMATEL methodology has been adopted to deal with expert's biasing and imprecise real scenario (Seçme et al., 2009; Gupta and Barua, 2018). The F-DEMATEL technique has following steps as explained below.

1. Generation of a fuzzy initial direct relational matrix (D). For calculating the level of interaction between the enablers a TFN scale has followed. As given in Figure 4, the membership function $\mu_{a}(x)$ is represented by y axis and TFN may be represented by $\mathrm{x}$ axis. Thus, TFN is represented by the triplet $(1, \mathrm{~m}, \mathrm{r})$, i.e. $(0,0.1,0.3)$ for (No relation) for , $(0.1,0.3,0.5)$ (Very Low relation), $(0.3,0.5,0.7)$ (Low relation), $(0.5,0.7,0.9)$ (High relation) and $(0.7,0.9,1)$ (Very High relation) respectively. 
333

334

335

336

337

338

340

341

342 if $x<l$

if $l \leq x \leq m$,

if $m \leq x \leq r$,

otherwise

0 ,

Thus, an initial direct relational matrix has been developed as D. In this enabler i affect the enabler $\mathrm{j}$ as: $\mathrm{D}=\left[d_{i j}\right]_{n \times n}$

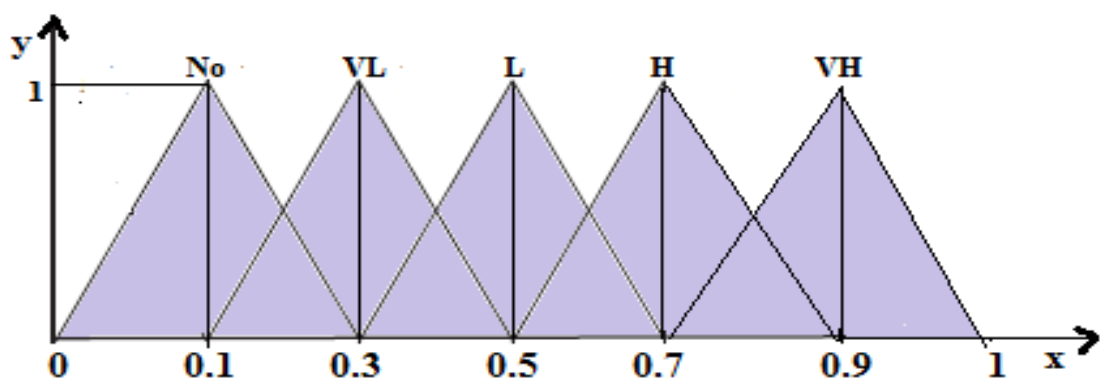

Figure 4: Triangular fuzzy numbers

2. Normalisation of direct relational table into normalised direct relational matrix $\mathrm{S}$ by using five steps as explained below (Opricovic and Tzeng, 2003). A five-step algorithm as follows for a particular fuzzy number $(1, \mathrm{~m}, \mathrm{r})$ :

Step1. Normalisation

$x r_{i j}^{n}=\left(r_{i j}^{n}-\operatorname{minl}_{i j}^{n}\right) / \Delta_{\min }^{\max }$

$x m_{i j}^{n}=\left(m_{i j}^{n}-\operatorname{minl}_{i j}^{n}\right) / \Delta_{\min }^{\max }$

$x l_{i j}^{n}=\left(l_{i j}^{n}-\min l_{i j}^{n}\right) / \Delta_{\min }^{\max }$

Step2. Compute right (rs) and left (ls) normalisation values:

$$
\begin{aligned}
& x r s_{i j}^{n}=x r_{i j}^{n} /\left(1+x r_{i j}^{n}-x m_{i j}^{n}\right) \\
& x l s_{i j}^{n}=x m_{i j}^{n} /\left(1+x m_{i j}^{n}-x l_{i j}^{n}\right)
\end{aligned}
$$

Step3. Compute total normalised crisp values:

$$
x_{i j}^{n}=\left[x l s_{i j}^{n}-\left(x l s_{i j}^{n} \times x l s_{i j}^{n}\right)+\left(x r s_{i j}^{n} \times x r s_{i j}^{n}\right)\right] /\left(1+x r s_{i j}^{n}-x l s_{i j}^{n}\right)
$$

Step4. Compute crisp values: 
357 Step5. Integrate crisp values:

$z_{i j}=\left(z_{i j}^{1}+z_{i j}^{2}+\ldots z_{i j}^{p}\right) / \mathrm{p}, \quad$ where $\mathrm{p}$ is numbers of decision makers

$359 \mathrm{~S}=\mathrm{k} \times \mathrm{D}$

Where, $\mathrm{k}=1 / \max _{1 \leq i \leq n} \sum_{j=1}^{n} d_{i j}$

361

362

363

364

365

366

367

368

369

370

371

372

373

374

375

376

377

378

379

380

381

382

383

384

3. Construct a total relation matrix $\mathrm{T}$ as: $\mathrm{T}=\mathrm{S}[I-S]^{-1}$, where $\mathrm{I}$ matrix is identity matrix

4. Drawing a cause and effect diagram. In this $x$ axis $(R+C)$ denotes the cause axis and $\mathrm{y}$ axis $(\mathrm{R}-\mathrm{C})$ denotes causal based effects axis as shown below:

$\mathrm{T}=\left[t_{i j}\right]_{n \times n}, \quad \mathrm{i}, \mathrm{j}=1,2 \ldots . . \mathrm{n}$

$\left[R_{i}\right]_{n \times 1}=\left(\sum_{j=1}^{n} t_{i j}\right)_{n \times 1}$

$\left[C_{j}\right]_{1 \times n}=\left(\sum_{i=1}^{n} t_{i j}\right)_{1 \times n}$

\section{Case Illustration}

This section includes a case study, questioner's development and finally numerical illustration. The case illustration consists of three sub-sections. These sub-sections are explained below in subsequent sections.

\subsection{Description of the Firm}

XYZ (fictitious name) act as a Focal Firm (FF) in a multitier system of AFSC which is located in India for delivering the perishable packed vegetables to most of the districts. Currently firm's processes consists of vegetables harvesting, food grains processing, packing and commercialisation of agri- product items consists of large varieties of cold storage based perishable products. Depending on consumer's requirement in different demographic regions, the packed products range from $5 \mathrm{Kg}$ to $40 \mathrm{Kg}$. Vegetables normally used as raw products are potatoes, fresh cabbages, peas, groundnuts, mushrooms and carrots. Most of the Food Processing Plants (FPP) of XYZ is situated at small distance from farmlands, which are dedicated for cultivating, cutting, packaging fresh vegetables by keeping in a cold ambient condition. Each processing plant has special facilities to a particular crop cultivations and cold storage of Work in Process Inventory (WIPI) to avoid spoilage. FF has one Main Processing Plant (MPP) for handling final packed agri products and distributions to retailers 
and end consumers. The whole multi-tier system of FF initiated from the planning of consumer's demands and ends by delivering of agri products to FF at the consumer's end. Based on IoT infrastructure, FF intended to directly approach tier 1 (Big retailers) and may directly/indirect controlled the lower tier (food processing, distribution and farmers) by itself and collaborating with external supports. This entire process is given in Figure 5 and Figure 6.

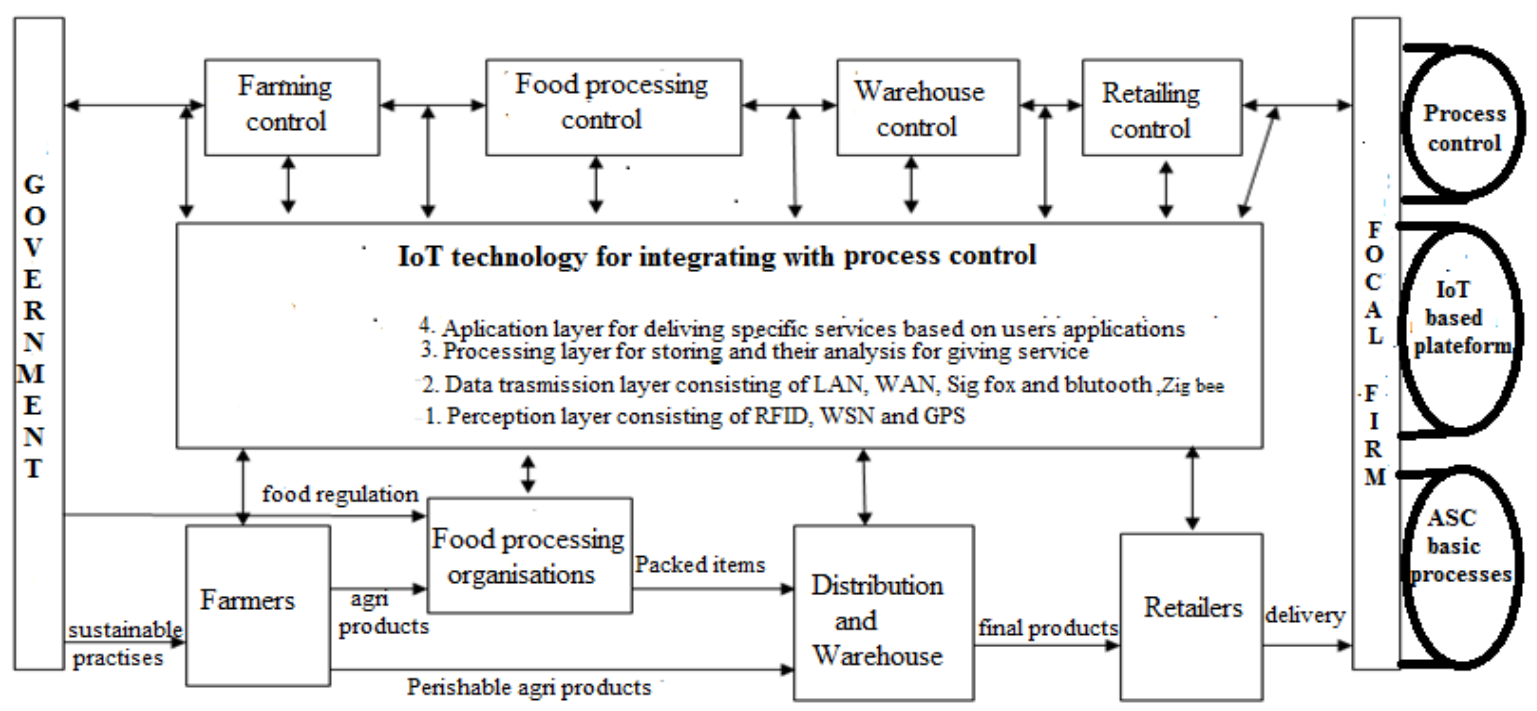

(Product flow)

Figure 5: Complete framework of the proposed case study for XYZ firm

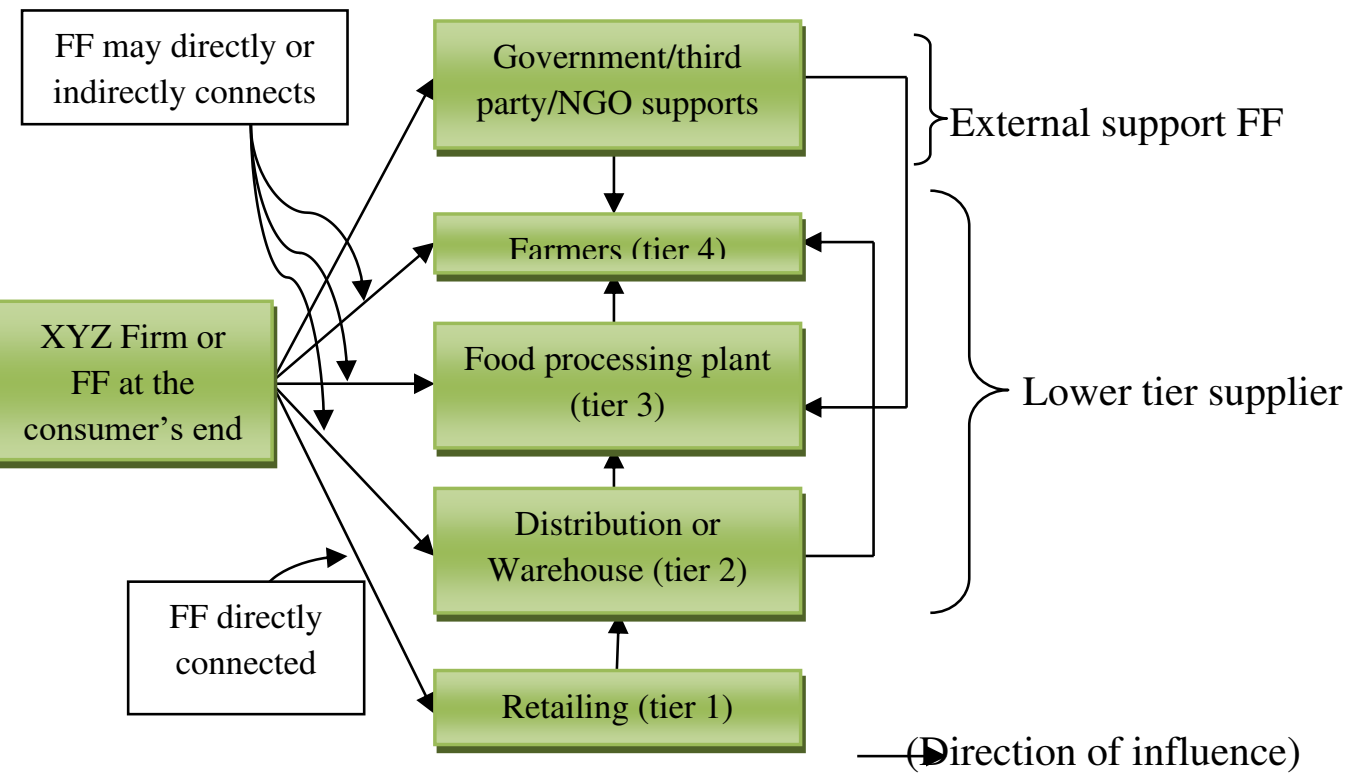


The XYZ firm has adopted IoT based infrastructure like developing technical manpower, IoT based cold chain, adopting various quality standards of food quality and safety in FF, finally supplying the packed and raw agri products to consumers. This case study of FF has needed to deal with any kind of natural disruption in agri food SC. Further, the FF has to meet the specific challenge of food SC for maintaining high perishable nature of fresh vegetables, meeting random demands from a specific area of high risk by disruption (COVID 19), meeting high standards of food safety and quality as per government regulations and standards (HACCP, ISO, GHP) with IoT based multi-tier sustainable development of entire AFSC.

\subsection{Questionnaire Development and Data Collection}

The framing of questions takes place based on the research panel of five experts to rate and analysis of the identified factors as shown in Appendix A. A total of 25 experts were approached from several case companies. In this context, a questionnaire was framed by considering all enablers in the literature and collect the response either through mail or postal. Out of 25 experts only 5 experts have filled their responses either through online or offline. Thus, 20 percent response rate has been used in this study. These participated 05 experts were categorised as their demographic characteristics. As per professional qualification level of experts, 02 experts were graduates, 02 were post graduate and 01 was doctorate. Most of the decisions makers (experts) were highly experienced ranging from5 to 25 years. Based on the filled questionnaire, the decisions makers involved in this research were the Logistics' Supervisors (E1), the Food and Worker Safety's Supervisors (E2), the Chief Executive Officers (E3) of government regulatory bodies for setting different standards (HACCP, GHP) for IoT based agri products production, processing, packing and handling, the agri-food procurement manager (E4) for managing strategies about placing order to farmers/suppliers for primary agri products like fresh vegetable and food grain , Research and Development (R\&D) team member (E5) having environmental (ISO 14001 standards) expertise and disaster management (ISO 37120 standards)expertise.

\subsection{Numerical Illustration}

This section explains the numerical illustration of the study. It consists of three sub section namely ISM application, DEAMATEL application and sensitivity analysis as explained below. 


\subsubsection{ISM application}

This section elaborates different steps of ISM by the means of numerical illustration. The complete sequence of procedure is given below.

\subsubsection{Structural self-interaction matrix}

For the establishment of the relationships among the enablers for developing IoT based sustainable security system, four notations have been applied for expressing the relationships among the enablers $\mathrm{i}$ and $\mathrm{j}$ as explained below.

$\mathrm{V}$ : Enabler i facilitating the Enabler j.

A: Enabler $\mathrm{j}$ facilitating the Enabler i.

$\mathrm{X}$ : Enabler $\mathrm{i}$ and $\mathrm{j}$ facilitating each other.

$\mathrm{O}$ : Enabler $\mathrm{i}$ and $\mathrm{j}$ are not related.

Experts given in sub-section 4.2 were requested to provide their agreement for framing of initial SSIM with the help of four notations as explained earlier. Based on the experts' response, initial SSIM for enablers is given in Table B1 of Annexure B.

\subsubsection{Initial and Final reachability matrix}

The SSIM has been transformed to an initial reachability matrix by placing the binary digits $(0,1)$ at the position of $\mathrm{V}, \mathrm{A}, \mathrm{X}$ and $\mathrm{O}$ for $(\mathrm{i}, \mathrm{j})$ as explained in below Table 2 .

Table 2: Notations and conversion of binary digits

\begin{tabular}{|c|c|c|}
\hline Notations in SSIM & Entry $(\mathbf{i}, \mathbf{j})$ in SSIM & Entry $(\mathbf{j}, \mathbf{i})$ in reachable matrix \\
\hline V & 1 & 0 \\
\hline A & 0 & 1 \\
\hline X & 1 & 1 \\
\hline O & 0 & 0 \\
\hline
\end{tabular}

The final reachability matrix is constructed based on the transitivity links as given in Table 3 .

Table 3: Final reachable matrix for enablers

\begin{tabular}{|c|c|c|c|c|c|c|c|c|c|c|c|c|c|c|c|}
\hline & C1 & C2 & C3 & C4 & C5 & C6 & C7 & C8 & C9 & C10 & C11 & C12 & C13 & C14 & DR.P \\
\hline C1 & 1 & $1^{*}$ & 1 & 1 & 1 & 1 & 1 & 1 & 1 & 1 & 1 & $1^{*}$ & 1 & 1 & 14 \\
\hline C2 & 0 & 1 & 0 & 1 & 1 & 1 & 1 & 1 & 1 & 1 & 1 & 1 & 1 & 1 & 12 \\
\hline C3 & 0 & $1^{*}$ & 1 & 1 & 1 & 1 & 1 & 1 & $1^{*}$ & $1^{*}$ & $1^{*}$ & $1^{*}$ & $1^{*}$ & 1 & 13 \\
\hline C4 & 0 & $1^{*}$ & 0 & 1 & 0 & 1 & 1 & $1^{*}$ & 1 & $1^{*}$ & $1^{*}$ & 1 & 1 & 1 & 11 \\
\hline C5 & 0 & $1^{*}$ & 0 & $1^{*}$ & 1 & 1 & 1 & 0 & 1 & 1 & $1^{*}$ & $1^{*}$ & $1^{*}$ & 1 & 11 \\
\hline C6 & 0 & 1 & 0 & 1 & $1^{*}$ & 1 & $1^{*}$ & $1^{*}$ & 1 & 1 & 1 & 1 & $1^{*}$ & 1 & 12 \\
\hline C7 & 0 & 0 & 0 & 0 & 0 & 0 & 1 & $1^{*}$ & 1 & 1 & 1 & 1 & 1 & 1 & 8 \\
\hline C8 & 0 & 0 & 0 & 0 & 0 & 0 & 1 & 1 & $1^{*}$ & 1 & 1 & 1 & $1^{*}$ & $1^{*}$ & 8 \\
\hline C9 & 0 & 0 & 0 & 0 & 0 & 0 & 0 & 0 & 1 & 1 & 1 & 0 & 0 & 1 & 4 \\
\hline
\end{tabular}




\begin{tabular}{|c|c|c|c|c|c|c|c|c|c|c|c|c|c|c|c|}
\hline C10 & 0 & 0 & 0 & 0 & 0 & 0 & 0 & 0 & 0 & 1 & 0 & 0 & 0 & 1 & 2 \\
\hline C11 & 0 & 0 & 0 & 0 & 0 & 0 & 0 & 0 & 1 & $1^{*}$ & 1 & 0 & 0 & $1^{*}$ & 4 \\
\hline C12 & 0 & 0 & 0 & 0 & 0 & 0 & $1^{*}$ & $1^{*}$ & 1 & $1^{*}$ & $1^{*}$ & 1 & 1 & $1^{*}$ & 8 \\
\hline C13 & 0 & 0 & 0 & 0 & 0 & 0 & 1 & 1 & 1 & $1^{*}$ & $1^{*}$ & $1^{*}$ & 1 & $1^{*}$ & 8 \\
\hline C14 & 0 & 0 & 0 & 0 & 0 & 0 & 0 & 0 & 0 & 0 & 0 & 0 & 0 & 1 & 1 \\
\hline DP.P & 1 & 6 & 2 & 6 & 5 & 6 & 10 & 9 & 12 & 13 & 12 & 10 & 10 & 14 & $116 / 116$ \\
\hline
\end{tabular}

466

\subsubsection{Levelling based partitions}

By using final reachability matrix the intersecting point of antecedent set (depending power) and reachability set (driving power) has determined. Iterating procedure will carry on for identifying each level as shown in Table 4.

Table 4: Initial iteration matrix for enablers

\begin{tabular}{|c|c|c|c|c|}
\hline & R.S & A.S & I.S & $\begin{array}{c}\text { Levels and } \\
\text { Iterations }\end{array}$ \\
\hline $\mathbf{1}$ & $1,2,3,4,5,6,7,8,9,10,11,12,13,14$ & 1 & 1 & LEVEL VII \\
\hline $\mathbf{2}$ & $2,4,5,6,7,8,9,10,11,12,13,14$ & $1,2,3,4,5,6$ & $2,4,5,6$ & LEVEL V \\
\hline $\mathbf{3}$ & $2,3,4,5,6,7,8,9,10,11,12,13,14$ & 1,3 & 3 & LEVEL VI \\
\hline $\mathbf{4}$ & $2,4,6,7,8,9,10,11,12,13,14$ & $1,2,3,4,5,6$ & $2,4,6$ & LEVEL V \\
\hline $\mathbf{5}$ & $2,4,5,6,7,9,10,11,12,13,14$ & $1,2,3,5,6$ & $2,5,6$ & LEVEL V \\
\hline $\mathbf{6}$ & $2,4,5,6,7,8,9,10,11,12,13,14$ & $1,2,3,4,5,6$ & $2,4,5,6$ & LEVEL V \\
\hline $\mathbf{7}$ & $7,8,9,10,11,12,13,14$ & $1,2,3,4,5,6,7,8,12,13$ & $7,8,12,13$ & LEVEL IV \\
\hline $\mathbf{8}$ & $7,8,9,10,11,12,13,14$ & $1,2,3,4,6,7,8,12,13$ & $7,8,12,13$ & LEVEL IV \\
\hline $\mathbf{9}$ & $9,10,11,14$ & $1,2,3,4,5,6,7,8,9,11,12,13$ & 9,11 & LEVEL III \\
\hline $\mathbf{1 0}$ & 10,14 & $1,2,3,4,5,6,7,8,9,10,11,12,13$ & 10 & LEVEL II \\
\hline $\mathbf{1 1}$ & $9,10,11,14$ & $1,2,3,4,5,6,7,8,9,11,12,13$ & 9,11 & LEVEL III \\
\hline $\mathbf{1 2}$ & $7,8,9,10,11,12,13,14$ & $1,2,3,4,5,6,7,8,12,13$ & $7,8,12,13$ & LEVEL IV \\
\hline $\mathbf{1 3}$ & $7,8,9,10,11,12,13,14$ & $1,2,3,4,5,6,7,8,12,13$ & $7,8,12,13$ & LEVEL IV \\
\hline $\mathbf{1 4}$ & 14 & $1,2,3,4,5,6,7,8,9.10,11,12,13,14$ & 14 & LEVEL I \\
\hline
\end{tabular}

\subsubsection{Classification of factors (MICMAC analysis)}

474 Cluster or sector formation of enablers mainly based on the value of driving and depending power as indicates in Figure 7.

This cluster formation is similar as given by Kamble et al. (2018b). The first cluster or quadrant is belongs to "autonomous variables" having weak driving and depending values. These variables are weakly linked with other enablers or negligible impact on the entire system developed by ISM approach. In this study, autonomous sector is empty suggesting that every enabler is weakly or strongly associated in the model. Second sector belongs to depending variables having high depending and low driving values. These variables require special focused. Enablers C9, C10, C11 and C14 are the part of this sector. 


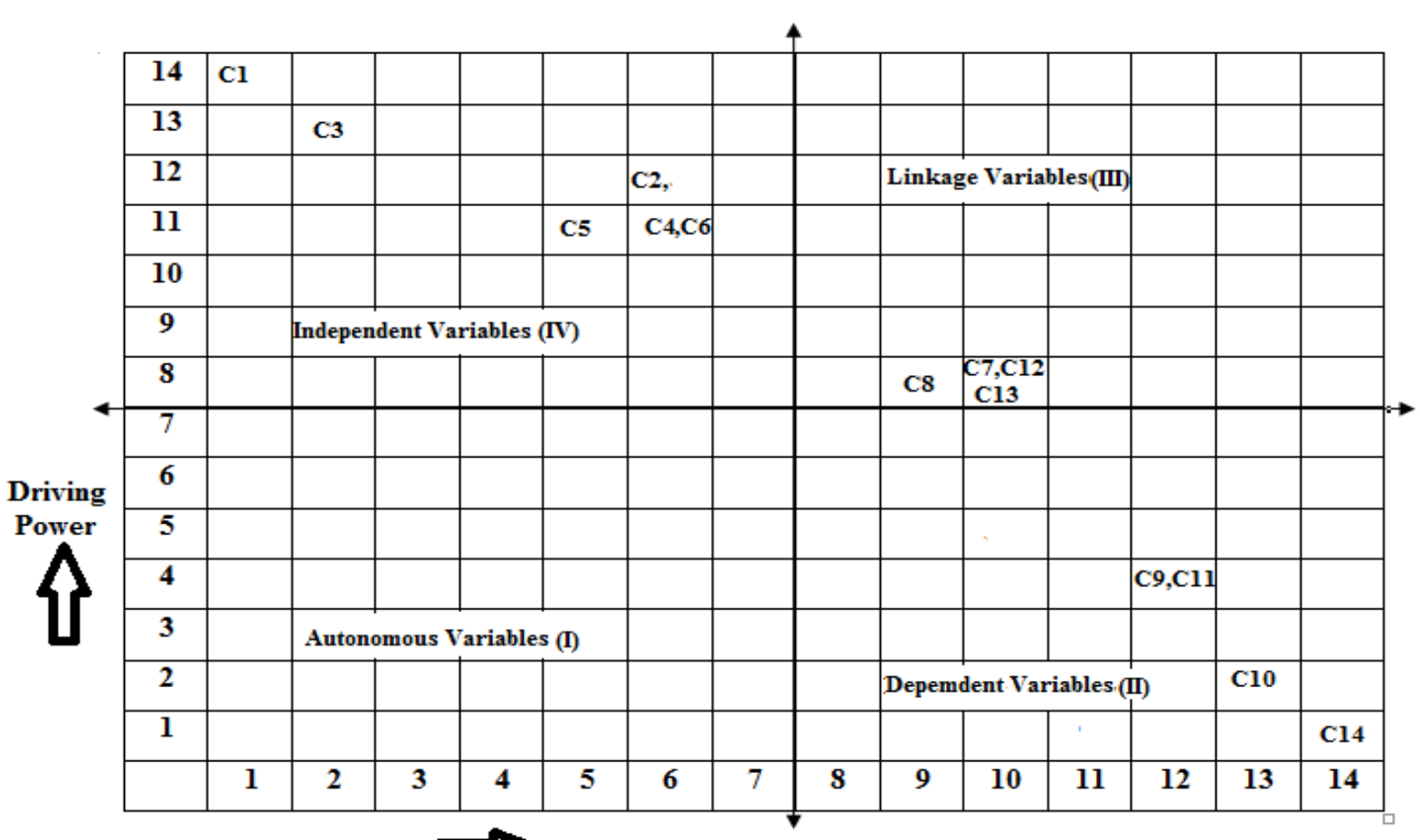

485

486

487

488

489

490

491

492

493

494

495

496

497

498

499

500

501

502

503

504

Figure 7: ISM based MICMAC analysis

Third sector belongs to linkage variables with high driving and depending values. These variables are unstable and having closed looping effect on other variables. Enablers C7, C8, $\mathrm{C} 12$ and $\mathrm{C} 13$ are the part of this sector. Fourth sector belongs to independent variables with high driving and low dependence power. Enablers C1, C2, C3, C4, C5 and C6 belong to this region. These variables require special planning of policies maker.

\subsubsection{ISM based hierarchical structure}

Based on the final reachability matrix (Table 3) and level partitioning (Table 4), an ISM based hierarchical model of enablers for IoT driven multitier sustainable food security system has been developed as depicted in Figure 8.

[Figure 8 about here]

\subsubsection{Fuzzy DEMATEL application}

After formulation of systematic structure by using ISM technique, the fuzzy DEMATEL methodology has been applied for developing cause and effect group for enablers. Fuzzy based approach handles the vagueness and biased expert's decisions. Step wise procedure of Fuzzy DEMATEL methodology is given below. 
505

506

507

508

509

510

511

512

513

514

515

516

517

518

519

520

521

522

523

524

525

526

527

528

529

530

531

532

533

\section{Sustainable based competitive ASC (C14)}

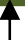

\section{Route optimisation (C10)}
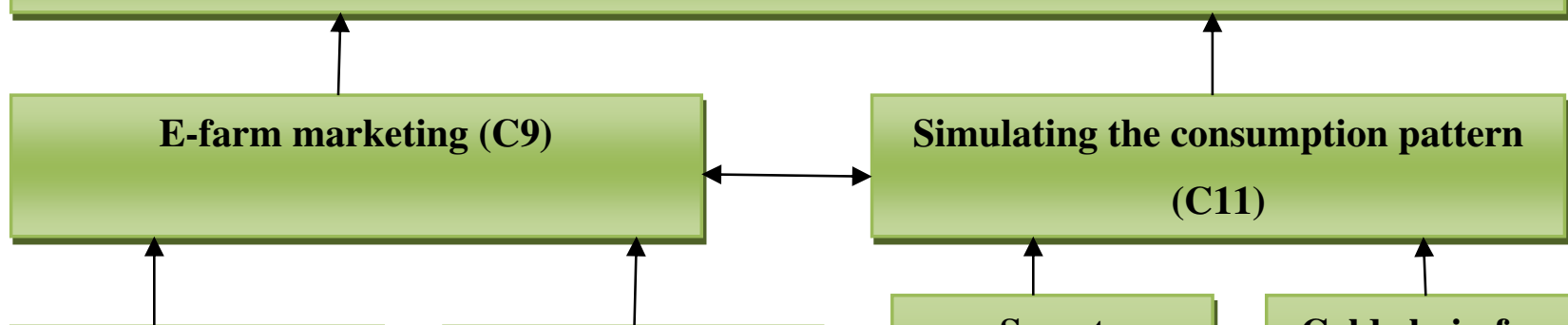

Simulating the consumption pattern

(C11)
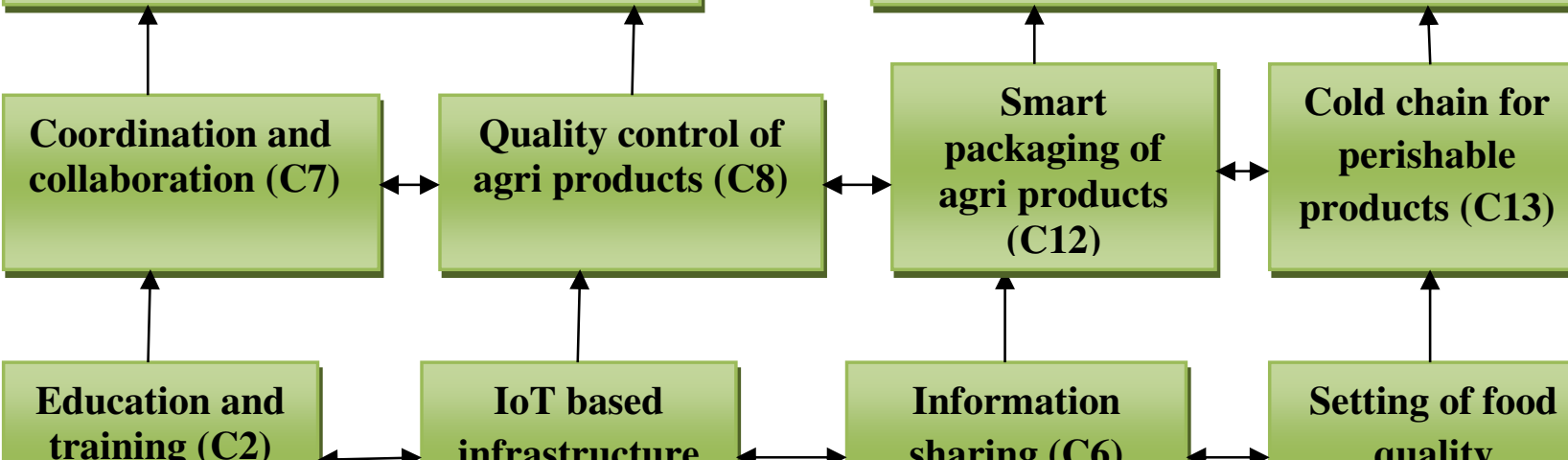

IoT based infrastructure

(C4)
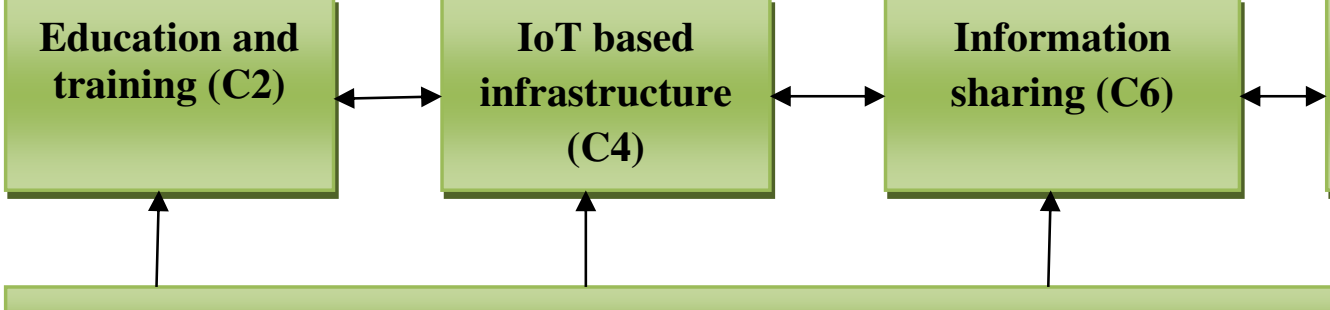

Setting of food quality standards (C5)

\section{Top management support (C3)}

\section{E-governance and policy (C1)}

Figure 8: ISM based hierarchical structure for showing dependencies

\subsubsection{Construct a direct relational matrix}

The experts given in sub section in 4.2 have given suggestions for the evaluation of the enablers in the pair wise matrix or direct relational matrix based on fuzzy linguistic variables.

\subsubsection{Construct a normalised direct relational matrix}

Normalisation of the aggregated direct relation matrix of TFN values suggested by the experts, by applying sub steps 1 to 5 of main step 2 explained in F- DEMATEL methodology as given in Table B2 of Annexure B. 
535 Total relational matrix has been developed based on the normalised matrix by using step 3. Determine $(\mathrm{R}+\mathrm{C})$ and $(\mathrm{R}-\mathrm{C})$ as given in 536 Table 5.

537 Table 5: Total direct relational matrix

\begin{tabular}{|c|c|c|c|c|c|c|c|c|c|c|c|c|c|c|c|c|c|}
\hline & C1 & C2 & C3 & C4 & C5 & C6 & C7 & C8 & C9 & C10 & C11 & C12 & C13 & C14 & $\mathbf{R}$ & $\mathbf{R}+\mathbf{C}$ & R-C \\
\hline C1 & 0.38577 & 0.53066 & 0.46559 & 0.44495 & 0.56086 & 0.45831 & 0.51733 & 0.52375 & 0.58458 & 0.63474 & 0.57326 & 0.52656 & 0.39986 & 0.64847 & 7.25471 & 12.70934 & 1.80008 \\
\hline C2 & 0.41964 & 0.46881 & 0.47744 & 0.45840 & 0.57468 & 0.46030 & 0.49140 & 0.49867 & 0.54576 & 0.64578 & 0.56929 & 0.55560 & 0.39484 & 0.64725 & 7.20787 & 13.88759 & 0.52815 \\
\hline $\mathrm{C} 3$ & 0.45503 & 0.56945 & 0.43613 & 0.47638 & 0.59920 & 0.47656 & 0.53129 & 0.54580 & 0.60642 & 0.64870 & 0.59837 & 0.57550 & 0.41932 & 0.68163 & 7.61979 & 13.50647 & 1.73310 \\
\hline C4 & 0.37556 & 0.48524 & 0.42057 & 0.38140 & 0.51682 & 0.43968 & 0.47756 & 0.47437 & 0.53814 & 0.58486 & 0.48333 & 0.48498 & 0.38937 & 0.60842 & 6.66030 & 12.51861 & 0.80199 \\
\hline C5 & 0.39915 & 0.51598 & 0.43224 & 0.43210 & 0.47549 & 0.44174 & 0.47280 & 0.47715 & 0.57046 & 0.60431 & 0.53155 & 0.45887 & 0.38264 & 0.62190 & 6.81637 & 13.97580 & -0.34306 \\
\hline C6 & 0.37047 & 0.45634 & 0.39124 & 0.39450 & 0.47385 & 0.35725 & 0.42824 & 0.43928 & 0.51647 & 0.54114 & 0.47436 & 0.47311 & 0.31059 & 0.55891 & 6.18576 & 12.07292 & 0.29860 \\
\hline C7 & 0.35505 & 0.42344 & 0.38020 & 0.38230 & 0.45354 & 0.36512 & 0.36190 & 0.43397 & 0.46995 & 0.51715 & 0.46071 & 0.44141 & 0.32171 & 0.47302 & 5.83944 & 12.16171 & -0.48284 \\
\hline C8 & 0.33190 & 0.43913 & 0.40424 & 0.38917 & 0.47581 & 0.38718 & 0.42563 & 0.38989 & 0.50301 & 0.54147 & 0.48231 & 0.44420 & 0.32548 & 0.55530 & 6.09472 & 12.66483 & -0.47539 \\
\hline C9 & 0.40263 & 0.44693 & 0.42077 & 0.42409 & 0.53809 & 0.43017 & 0.46679 & 0.47711 & 0.49269 & 0.59836 & 0.54101 & 0.52407 & 0.36809 & 0.60600 & 6.73680 & 14.25985 & -0.78625 \\
\hline C10 & 0.40416 & 0.48299 & 0.40223 & 0.44998 & 0.54668 & 0.43012 & 0.45841 & 0.49412 & 0.56044 & 0.53790 & 0.51830 & 0.51688 & 0.36798 & 0.62157 & 6.79176 & 14.98632 & -1.40280 \\
\hline C11 & 0.38881 & 0.46166 & 0.41321 & 0.39441 & 0.49379 & 0.42933 & 0.43583 & 0.47104 & 0.54196 & 0.58706 & 0.45905 & 0.47767 & 0.38377 & 0.60119 & 6.53878 & 13.77128 & -0.69373 \\
\hline C12 & 0.42273 & 0.52864 & 0.46867 & 0.45686 & 0.50852 & 0.45579 & 0.46439 & 0.50442 & 0.59319 & 0.63946 & 0.56415 & 0.47802 & 0.39011 & 0.64843 & 7.12338 & 14.00983 & 0.23693 \\
\hline C13 & 0.35076 & 0.40459 & 0.37587 & 0.36451 & 0.44297 & 0.34343 & 0.37667 & 0.39947 & 0.47855 & 0.52983 & 0.46268 & 0.44742 & 0.29195 & 0.52230 & 5.79099 & 10.88510 & 0.69688 \\
\hline C14 & 0.39297 & 0.46587 & 0.39832 & 0.40925 & 0.49912 & 0.41218 & 0.41405 & 0.44105 & 0.52143 & 0.58377 & 0.51415 & 0.48215 & 0.34840 & 0.51602 & 6.39873 & 14.70913 & -1.91168 \\
\hline C & 5.45463 & 6.67972 & 5.88669 & 5.85831 & 7.15943 & 5.88716 & 6.32228 & 6.57011 & 7.52305 & 8.19456 & 7.23251 & 6.88645 & 5.09411 & 8.31040 & & & \\
\hline
\end{tabular}

\section{4.3.2.4 Cause and effect diagram}

540 Construct a cause and effect diagram of the enablers by using $(\mathrm{R}+\mathrm{C})$ and $(\mathrm{R}-\mathrm{C})$ values. By using Figure 9, it may be concluded that

541 enablers C5, C8, C7, C11, C9, C10 and C14 are categorised into effect group. Similarly, enablers C1, C3, C4, C13, C2, C6 and C12 542 categorised into cause group. 


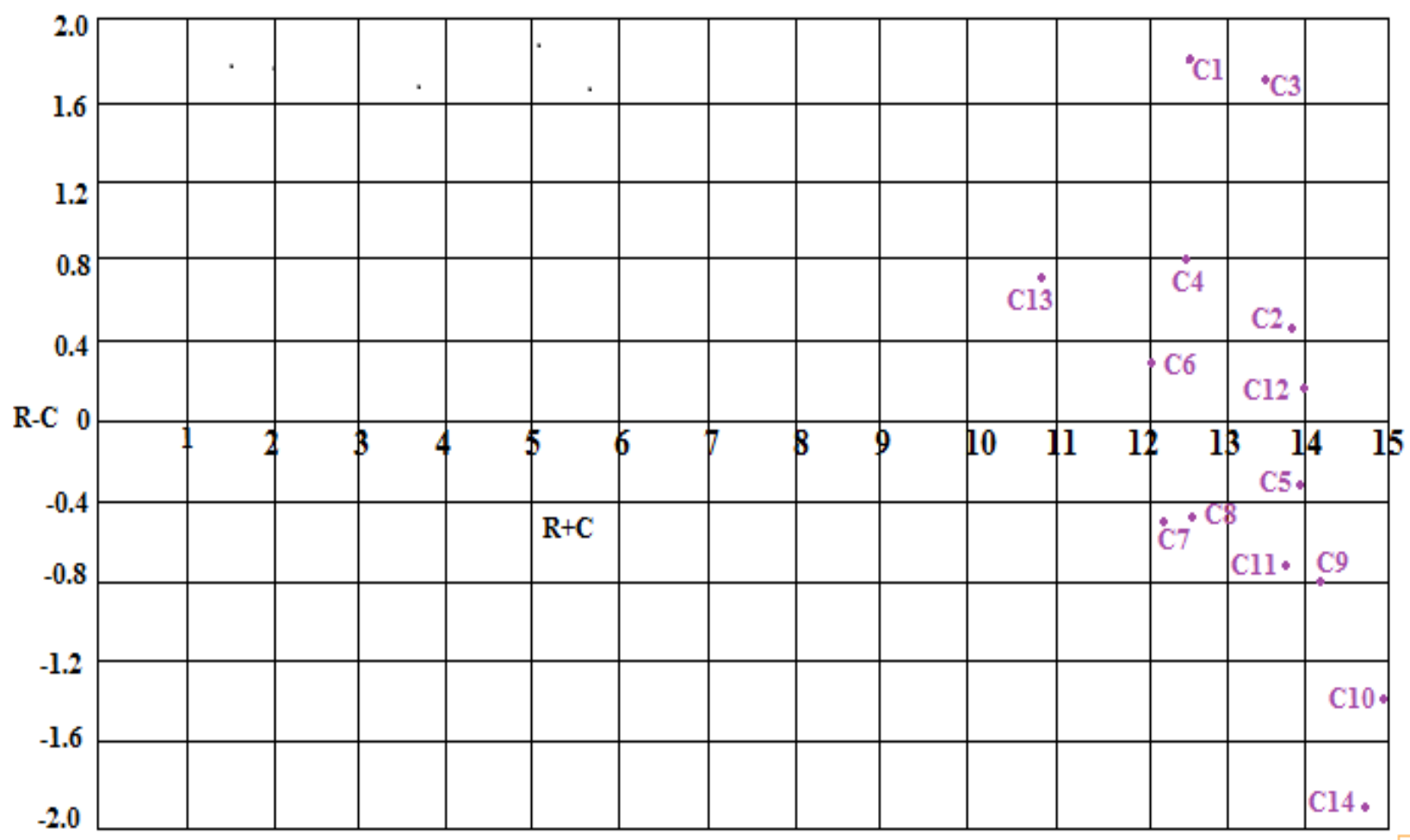

Figure 9: The cause and effect diagram of enablers

\subsubsection{Sensitivity analysis}

Sensitivity analysis has been done for checking the validity and robustness of the results obtained based on experts opinions (Raja Ambedkar et al., 2018). Sensitivity checking also helps in determination of any biasing by a specific expert, which may alter the final results of the research. Therefore, this paper has applied the above analysis by changing the weights given by the experts for a particular case to analysis the overall impact on the results. The sensitivity analysis has been done by providing higher weightage to one expert and giving the equally divided weightage to rest of four experts. In the same manner five different runs have been performed as shown in Table 6.

Table 6: Weightage assigned to the experts during sensitivity analysis

\begin{tabular}{|c|c|c|c|c|c|}
\hline Sensitivity Run & Expert 1 & Expert 2 & Expert 3 & Expert 4 & Expert 5 \\
\hline Run 1 & 0.40 & 0.15 & 0.15 & 0.15 & 0.15 \\
\hline Run 2 & 0.15 & 0.40 & 0.15 & 0.15 & 0.15 \\
\hline Run 3 & 0.15 & 0.15 & 0.40 & 0.15 & 0.15 \\
\hline Run 4 & 0.15 & 0.15 & 0.15 & 0.40 & 0.15 \\
\hline Run 5 & 0.15 & 0.15 & 0.15 & 0.15 & 0.40 \\
\hline Current case & 0.20 & 0.20 & 0.20 & 0.20 & 0.20 \\
\hline
\end{tabular}


557 For each run, different total relational ([T]) matrix has been constructed by using direct relational 558 matrix ([D]) based on the expert's weightage. In all of the five scenarios, C1, C3, C4, C13, C2 559 and C6 are categorised into cause group. Similarly, C5, C8, C7, C11, C9, C10 and C14 are 560 categorised into effect group. Nevertheless, C12 is categorised into effect group in scenario 2 and 561 scenario 5. Similarly, C12 is categorised into caused group for other scenario. Thus, C12 is 562 highly sensitive. The complete sensitivity results have shown in Table 7.

563 Table 7: (R-C) results given by different experts during sensitivity analysis

\begin{tabular}{|c|c|c|c|c|c|c|}
\hline Factors & Current & Scenerio1 & Scenerio2 & Scenerio3 & Scenerio4 & Scenerio5 \\
\hline C1 & 1.80008 & 1.712181 & 2.156665 & 1.599417 & 2.497553 & 2.675488 \\
\hline C2 & 0.52815 & 0.378821 & 0.572488 & 0.502497 & 1.011352 & 0.774436 \\
\hline C3 & 1.73310 & 1.65859 & 2.188308 & 1.980074 & 1.577325 & 1.458863 \\
\hline C4 & 0.80199 & 0.805325 & 1.079415 & 0.558955 & 0.982139 & 1.184376 \\
\hline C5 & -0.34306 & -0.42728 & -0.47154 & -0.15221 & -0.61596 & -0.31443 \\
\hline C6 & 0.29860 & 0.349853 & 0.602748 & 0.345508 & 0.809607 & 1.442452 \\
\hline C7 & -0.48284 & -0.32971 & -0.29271 & -0.12641 & -1.27413 & -1.04767 \\
\hline C8 & -0.47539 & -0.42918 & -0.51209 & -0.66055 & -0.4806 & -0.80603 \\
\hline C9 & -0.78625 & -0.86447 & -1.4014 & -0.63638 & -0.98969 & -0.53108 \\
\hline C10 & -1.40280 & -1.00089 & -2.19216 & -1.80199 & -1.7247 & -3.31767 \\
\hline C11 & -0.69373 & -0.86032 & -0.76005 & -0.8316 & -1.18357 & -0.4487 \\
\hline C12 & 0.23693 & 0.258529 & -0.04325 & 0.521446 & 0.79652 & -0.06022 \\
\hline C13 & 0.69688 & 0.310889 & 1.137867 & 0.573901 & 1.772701 & 2.185324 \\
\hline C14 & -1.91168 & -1.56234 & -2.06429 & -1.87265 & -3.17855 & -3.19513 \\
\hline
\end{tabular}

564

565 The R-C graphs have shown in Figure 10.

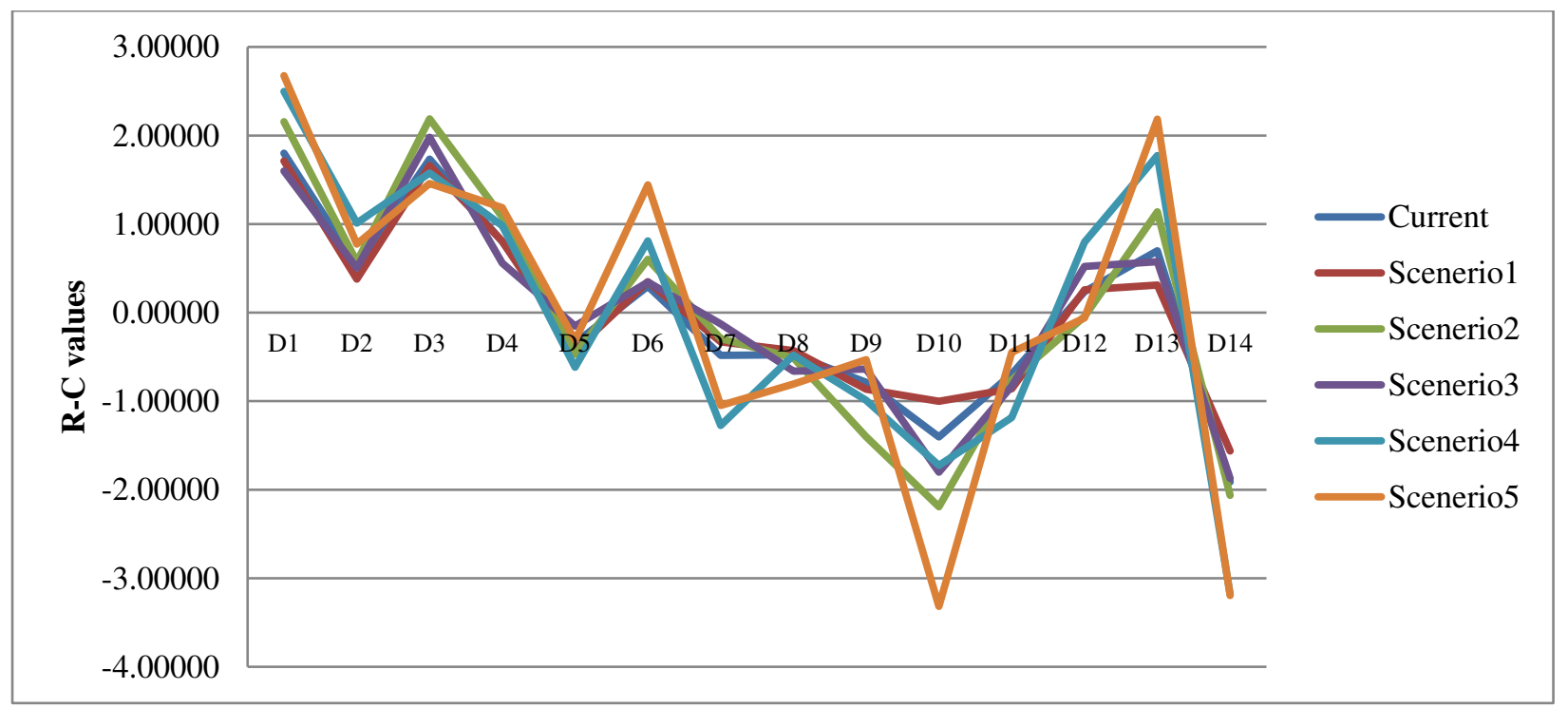

Figure 10: Sensitivity analysis of $(\mathrm{R}-\mathrm{C})$ values 


\section{Discussion of Findings}

570 Globalised based fragmenting of AFSC sustainability, along with increased stakeholder's 571 demands for increasing transparency and food security, have increased the involvement of lower 572 tier or sub-supplier for ensuring sustainability (Miemczyket al., 2012). Nevertheless, the majority 573 of severe sustainable issues in the AFSC are frequently regenerated by lower tier-suppliers 574 positioned in the second tier or further upstream (Grimm et al., 2011; Gunasekaran et al., 575 2014).This paper identified the important enablers of IoT based sustainable multi-tier food 576 security system in AFSC and linking it to global sustainable outcomes. Finally, interdependent 577 enablers were analysed based on ISM and DEMATEL technique.

578 E-governance and policy (C1) is the most important cause group based on (R-C) value and 579 classified into independent variable based on driving and dependence power. In the developing countries, sustainability's issues of AFSC are mainly ensured by governments' authorities. These authorities controlled the various stages of AFSC for assuring sustainable progress of SCM by 582 avoiding procuring delays and food frauds resulting agri-food secure system especially when

583 584 585 586

587

588 589 590 591 592 593 594 595 596 597 598 dealing with global distribution of multi-tier system (Ganasegeran and Abdulrahman, 2020). Top management support (C3) is the second important caused group and classified into independent variable. It may provide proper training to lower supplier, mainly responsible for sustainable issues about awareness on global environmental regulations and standards, pollutants reducing by following ISO14000 series (Jayasinghe et al., 2019).

IoT based infrastructure (C4) is the third important cause group and clustered in independent variable. IoT based infrastructure systems provide important data of government and organisational data for decision taking by the FF about global demand fluctuation, regulating quality standards, monitoring for adjusting logistics action before any accidents (DaneshvarKakhki and Gargeya, 2019). Cold chain for perishable products (C13) is the fourth important cause group and categorised under linkage variable. This finding may be validated as India needs cold storage round of 61.13 million metric tons but it has capacity only 32 million metric tons (Times of India, 2014). Thus it has shortage of 50\% cold capacity. Cold storage is required for controlling the quality of AFSC by reducing the degrading of agri food and less contaminating of processes. Jose and Shanmugam, (2019) noticed that degrading of agri food from post harvested stage to consumers hand mostly occur due to low cold storage system. 
Education and Training (C2) is the fifth important cause group and categorised into independent variables. This finding may be validated as it empowers the farmers and other workers of food organisation about the new emerging technologies and other global sustainable practices provided by third parties collaboration (Mangla et al., 2017). Information sharing (C6) is the sixth important cause group and categorised into independent variable. Effective information leads to proper communication among the multi-tier suppliers located globally in the SCM has reduced responsive time to any disrupting event in SC (Ivanov and Dolgui, 2020; Dun and Bradstreet, 2020).Smart packaging of agri products (C12) is the seventh important cause group and act as linkage variable. Agri based perishable-products needs extra protection during handling and palletising, this may be possible sensor based smart packing (Corkery and Gelles, 2020). It may further provide protection of packed agri products against food loose due to thermal degradation during transportation in humid climate condition of different countries (Shukla et al., 2014).

Sustainable based competitive ASC (C14) is the most important influenced group based on (RC) value and classified into dependent variable based on the driving and dependent power. Sustainable based competitiveness for AFSC means considering sustainable practices at operational, tactical and strategies level for yielding both socio- economic and environmentalbuild competitiveness (Singh et al., 2019; Krishnan et al., 2020). Similarly, Route optimisation (C10) is the second important influenced group and classified into dependent variable. Route optimisation enhances the competence of appropriately meeting the order which included avoiding the delays of orders, effectively managing lead times, reliable delivering. Further, route optimisation may reduce GHG emissions which may lead to environmental based global sustainable practices specifically in any epidemic outbreak (Farahani et al., 2020; Mishra et al., 2018). E-farm marketing (C9) is at third important effect group and comes under dependent variable category. This finding may be justified as the wastage in the AFSC mostly occurs due the large numbers of intermediates stakeholders as the number of intermediates increased; switching of agri food reserve will be increased from one stakeholder to another, results in degrading losses of agri food (Schanes et al., 2018).

Simulating the consumption pattern $(\mathrm{C} 11)$ is the fourth important effect group and classified into dependent variable. It may help in improving the distribution channels for route optimisation at global level for improving social and environmental sustainability. It may also regulate the prices 
based on daily demands of agri food and logistics facilities. Coordination and collaboration (C7) is the fifth important effect group and classified into linkage variable. Coordination enclosed the channels of union and secure inter-relationship together with jointly decision taking and collaborating for ensuring common sustainable goals by integrating local SCM and global SCM (Agyemang et al., 2018). Quality control of agri products (C8) is sixth important effect group and classified into linkage variable. It may segregate the agri-food products based on their origination, procuring dates, processing's lots etc. (Shih and Wang, 2016). Setting of food quality standards (C5) is the seventh important effect group and categorised into independent variable. Even though, food regulatory bodies like Food Safety Standards Authority of India (FSSAI) have provides standards, not every stakeholders of AFSC are fully aware about standardised procedure of food processing and packaging (Joshi et al., 2009).

Finally, sensitivity analysis has allowed the experts to consider the robustness of their decisions. Smart packaging of agri products $(\mathrm{C} 12)$ is the most sensitive enabler. C12 is categorised into effect group in scenario 2 and scenario 5. Similarly, C12 is categorised into caused group for other scenario. Thus, C12 is highly sensitive.

\subsection{Managerial and Practitioners Implications}

In lieu of current going outbreak (COVID 19), this work seeks for identification of variables for modelling of an IoT based AFSC sustainability. This research attempts to establish the interrelationships and cause and effect analysis of the identified, which may help managers in reducing the wastage and improved the quality of agri food products throughout the AFSC for ensuring multitier sustainable based competiveness as well as to other agri-food organisations. The finding suggests some managerial implications in effectively managing IoT based AFSC for achieving sustainable based food security. First, this research may guide the managers of FF to decide the managing strategies of the lower and upper tier suppliers e.g. either to adopt direct evaluation (casual inspection or auditing) or collaboration (worker's training and implementing sustainable practices).

It may help the managers to consider IoT for multi-tier system in effectively information's sharing among food regulatory bodies and other multi-tier suppliers. IoT infrastructure may guide the managers in the transportation of grains and perishable vegetables from excess cultivation regions to deficient regions. Further, the use of IoT based online procurement (e- 
661 farming) may facilitate the efficient distribution by reducing the mediators or small retailers

662 during the whole AFSC.

663 This study may guide the managers for effective training of employee in adapting technologies 664 involved in the cold chain, food handling for maintaining the quality of products. This research 665 will further guide the managers for improving the packaging standards of agri products to 666 enhance the qualities of agri-products and waste reduction during the transporting and 667 warehousing stages. Improved packaging may help the managers in their products branding for 668 better product management at the globalised level. The initiatives such as RFID and BDA 669 technology will help managers in prediction of crop yield and demand pattern. Forecasting of

670 crop yield may help the managers in policy making for storage, processing, packaging etc.

671 Similarly, forecasting of demand pattern may guide the managers for their logistics planning.

672 Thus, by investing in the IoT implementation for multi-tier system, managers have built up their

673 firm's effectiveness for serving the upstream practices (farming, food processing, and storage)

674 and downstream (retailers, consumers) in a better manner. Further, managers may get 675 collaborated with non-profits NGOs and other third parties for facilitating the achievement of 676 their global sustainable outcomes. It may guide the managers for the planning of feasible IoT 677 technology in managing food security and safety under current on-going epidemics (COVID 19) 678 in lieu with customer satisfaction and new horizons of profitability.

679

\subsection{Unique Contribution}

681 The research develops an IoT based multi-tier sustainable food security model for integrating 682 sustainable and global AFSC. In any natural epidemics outbreaks (COVID 19), this research has 683 focused both on agri-food production and optimised distributing system by going beyond tier 1 684 supplier. Thus, this research may help in reduction of GHG emission from lower tier/upstream 685 and food wastage for attaining environmental and socio-economic based global sustainability 686 within AFSC.

687 This research may be act as very initial step for providing sufficient food grains/products to 688 growing populations with improved technology based farming practices and reduced farmlands.

689 Further, this paper proposed quantitative view for developing the hierarchical inter-relationships 690 between enablers of IoT based agri-food security system based on ISM-DEMATEL approach. 


\section{Conclusion}

693 The world has been paused in the central of globalised disruptive risk (COVID 19). Currently, 694 AFSC has facing the global risk of food security and sustainability due to high flexibility in 695 consumer demand and breaking off SC links. To tackle the above issues, this research proposed a

696

697

698

699

700

701

702

703

704

705

706

707

708

709

710

711

712

713

714

715

716

717

718

719

720

721

722 systematically arranged structure with cause and effect strength for the variables involved in IoTdriven AFSC sustainability. Thus, the objective of this paper is ensuring globalised sustainability based on the collaboration of multi-tier system by using different configurations of multi-tier system and governing mechanisms based on several IoT technologies. In this sense, this paper has identified fourteen enablers through literature. These enablers were evaluated by using ISM and Fuzzy- DEMATEL.

Finally, sensitivity analysis has been done for checking the robustness of the result or experts accuracy. Based on sensitivity analysis, it has been noticed that in all five scenario, $\mathrm{C} 13$ enablers have got first rank and $\mathrm{C} 14$ has ranked fourteen. Further, enablers $\mathrm{C} 11$ and $\mathrm{C} 10$ are the most sensitive enablers. The research framework presented in this paper has validated by taking a case company (XYZ) of perishable agri products.

Though, the present has given some important results, the present paper still has some limitations. In the present paper, the combined ISM-DEMATEL approach has taken only fourteen enablers for IoT driven food security system or AFSC sustainability. The developed model in this paper is highly dependent on the experts' opinions. Further, the proposed framework in this research is not a generalised view for dairy items, meat and pulses, which are in demands at global level. Further, in future more enablers may be taken by using some validation model like structural equation modelling. In future, this research model may extend to some other SC of dairy items by taking deeper tier or suppliers.

\section{REFERENCES}

Aboah, J., M.M.J. Wilson, K. Bicknell, and K.M. Rich. 2019. "Identifying the precursors of vulnerability in agricultural value chains: A system dynamics approach." International Journal of Production Research. https://doi.org/10.1080/00207543.2019.1704592.

Achabou, M.A., S. Dekhili, and M. Hamdoun. 2017. "Environmental upgrading of developing country firms in global value chains." Business Strategy and the Environment 26 (2):224238. 
Agyemang, M., Q. Zhu, M. Adzanyo, E. Antarciuc, and S. Zhao 2018."Evaluating barriers to green supply chain redesign and implementation of related practices in the West Africa cashew industry." Resources, Conservation and Recycling 136: 209-222.

Ahmad, M.T., and S. Mondal. 2019. "Dynamic supplier selection through optimal ranking under two echelon system.” Benchmarking: An International Journal 26 (8): 2574-2607.

Allaoui, H., Y. Guo, A. Choudhary, and J. Bloemhof. 2018. "Sustainable agro-food supply chain design using two-stage hybrid multi-objective decision-making approach." Computers and Operations Research 89: 369-384.

Araz, O. M., T.-M. Choi, D. Olson, and F. S. Salman. 2020. "Data analytics for operational risk management." Decision Sciences. Forthcoming, https://doi.org/10.1111/deci.12443

Armanda, D.T., J.B. Guinée, and A. Tukker 2019. “The second green revolution: Innovative urban agriculture's contribution to food security and sustainability - A review." Global Food Security 22, 13-24.

Atzori, L., Iera, A, and G. Morabito. 2010. "The internet of things: a survey." Computer Networks 54 (15): 2787-2805.

Badami, M.G., and N. Ramankutty. 2015. "Urban agriculture and food security: a critique based on an assessment of urban land constraints." Global Food Security 4, 8-15. https:// doi.org/10.1016/j.gfs.2014.10.003.

Baumer-Cardoso, M., L. Campos, F. Santos, E. Frazzon. 2020. "Simulation-based analysis of catalysers and trade-offs in lean and Green manufacturing." Journal of Cleaner Production 242 (5): 118411

Ben-Daya, M., Hassini, E. and Z. Bahroun. 2019. "Internet of things and supply chain management: a literature review." International Journal of Production Research 57 (1516): 4719-4742.

Benis, K., and P. Ferrão. 2018. "Commercial farming within the urban built environment taking stock of an evolving field in northern countries." Global Food Security 17, 30-37. https://doi.org/10.1016/j.gfs.2018.03.005.

Bosona, T., and G. Gebresenbet. 2013. "Food traceability as an integral part of logistics management in food and agricultural supply chain." Food Control 33(10): 32-48.

Busse, C., M. Schleper, M. Niu, and S.M. Wagner. 2016. "Supplier development for sustainability: contextual barriers in global supply chains." International Journal of 
Physical Distribution and Logistics Management 46 (11): 442-468.

755

756

757

758

759

760

761

762

763

764

765

766

767

768

769

770

771

772

773

774

775

776

777

778

779

780

781

782

783

784
Bustos, C.A., and E. H. Moors. 2018. "Reducing post-harvest food losses through innovative collaboration: insights from the Colombian and Mexican avocado supply chains." Journal of Cleaner Production 199 (6): 1020-1034.

Chaple, A.P., B.E. Narkhede, M.M. Akarte, and R. Raut. 2018. "Interpretive framework for analysing lean implementation using ISM and IRP modeling." Benchmarking: An International Journal 25 (9): 3406-3442.

Chauhan, A., A. Singh, and S. Jharkharia. 2018. "An ISM and DEMATEL method approach for the analysis of barriers of waste recycling in India." Journal of Air Waste Management 68 (2): 100-110.

Choi, T.M., X. Wen, X. Sun, and S.H. Chung. 2019. "The mean-variance approach for global supply chain risk analysis with air logistics in the block chain technology era." Transportation Research Part E: Logistics Transportation Review 127: 178-191.

Clarke, T., and M. Boersma. 2017. "The governance of global value chains: unresolved human rights, environmental and ethical dilemmas in the Apple supply chain." Journal of Business Ethics 143: 111-131.

Cohen, M. 2020. Does the COVID-19 outbreak mark the onset of a sustainable consumption transition? Sustainability 16 (1): 1-3.

Corkery, M., and D. Gelles. 2020. "Robots welcome to take over, as pandemic accelerates automation." The New York Times April 10. https://www.nytimes.com/2020/04/10/ business/coronavirus-workplace-automation.html (Last Accessed April 27, 2020).

DaneshvarKakhki, M., and V.B. Gargeya. 2019. "Information systems for supply chain management: a systematic literature analysis." International Journal of Production Research 57(15-16): 5318-5339.

Dev, N., R.Shankar, and F. Qaiser. 2020. "Industry 4.0 and circular economy: operational excellence for sustainable reverse supply chain performance." Resource Conservation and Recycling 153: 104583.

Dolgui, A., D. Ivanov, and B. Sokolov. 2018. "Ripple effect in the supply chain: An analysis and recent literature.” International Journal of Production Research 56 (1-2): 414-430.

Dolgui, A., D. Ivanov, and M. Rozhkov. 2020. "Does the ripple effect influence the bullwhip effect? An integrated analysis of structural and operational dynamics in the supply chain.” 
International Journal of Production Research 58 (5): 1285-1301.

Dos Muchangos, L.S., A. Tokai, and A. Hanashima. 2015. "Analyzing the structure of barriers to municipal solid waste management policy planning in Maputo city, Mozambique." Environmental Development 16: 76-89.

Dun and Bradstreet.2020. https://foreignpolicy.com/2020/03/04/blindsided-on-the-supply-side/ accessed on March 10, 2020.

Fanzo, J. 2015. "Ethical issues for human nutrition in the context of global food security and sustainable development." Global Food Security 7, 15-23.

Farahani, R.Z., M.M. Lotfi, and S. Rezapour. 2020. "Mass casualty management in disaster scene: A systematic review of OR\&MS research in humanitarian operations." European Journal of Operation Research, https://doi.org/10.1016/j.ejor.2020.03.005.

Formentini, M., and P. Taticchi. 2016. "Corporate sustainability approaches and governance mechanisms in sustainable supply chain management." Journal of Cleaner Production 112: $1920-1933$.

Fuglie, K. 2016. "The growing role of the private sector in agricultural research and development world-wide." Global Food Security 10, 29-38.

Ganasegeran, K., and S.A. Abdulrahman. 2020. "Artificial intelligence applications in tracking health behaviours during disease epidemics." In: Human Behaviour Analysis Using Intelligent Systems. Springer: 141-155.

Grimm, J.H., J.S. Hofstetter, and J. Sarkis. 2014. "Critical factors for sub-supplier management: a sustainable food supply chains perspective." International Journal of Production Economics 152 (1): 159-173.

Gunasekaran, A., Z. Irani, and T. Papadopoulos. 2014. "Modelling and analysis of sustainable operations management: certain investigations for research and applications." Journal of the Operational Research Society 65(6):806-823.

Gupta, H., and M. Barua. 2018. "A grey DEMATEL-based approach for modeling enablers of green innovation in manufacturing organizations." Environmental Science and Pollution Research 25 (10): 9556-9578.

Gupta, V., and D. Ivanov. 2020. "Dual sourcing under supply disruption with risk-averse suppliers in the sharing economy." International Journal of Production Research 58 (1): 291-307. 
Gwynn-Jones, D., H. Dunne, I. Donnison, P. Robson, G.M. Sanfratello, B. Schlarb-Ridley, K. Hughes, and P. Convey. 2018. "Can the optimization of pop-up agriculture in remote communities help feed the world?" Global Food Security 18, 35-43. https://doi.org/ 10.1016/j.gfs.2018.07.003.

Harbour, L. 2020."The Coronavirus Impact on the Global Automotive Supply Chains." Accessed March 24, 2020.https://www.forbes.com/sites/laurieharbour1/ 2020/03/13/thecoronavirus-impact-on-the-global-automotive-supply-chain/185153c 8444e.

Hartmann, J., and S. Moeller, S. 2014. "Chain liability in multitier supply chains? Responsibility attributions for unsustainable supplier behaviour." Journal of Operation Management 32: 281-294.

Ho, W., T. Zheng, Yildiz, and S. Talluri. 2015. "Supply Chain Risk Management: A Literature Review." International Journal of Production Research 53 (16): 5031-5069.

Hosseini, S., D. Ivanov, and A. Dolgui. 2019. "Review of quantitative methods for supply chain resilience analysis." Transportation Research Part E 125: 285-307.

Hsu, C.W., T.C. Kuo, S.H. Chen, and A.H. Hu, 2013. "Using DEMATEL to develop a carbon management model of supplier selection in green supply chain management." Journal of Cleaner Production 56:164-172.

Irani, Z. and A.M. Sharif. (2016). "Sustainable food security futures: perspectives on food waste and information across the food supply chain." Journal of Enterprise Information Management 29 (2): 171-178.

Ivanov, D. 2020. "A blessing in disguise" or "as if it wasn't hard enough already": Reciprocal and aggravate vulnerabilities in the supply chain." International Journal of Production Research, https://doi.org/10.1080/00207543.2019.1634850.

Ivanov, D., and A. Dolgui, 2020."A digital supply chain twin for managing the disruptions risks and resilience in the era of Industry 4.0." Production Planning Control forthcoming, https://doi.org/10.1080/09537287.2020.1768450

Ivanov, D., and A. Dolgui. 2019. "Low-Certainty-Need (LCN) supply chains: A new perspective in managing disruption risks and resilience." International Journal of Production Research 57 (15-16): 5119-5136.

Jayasinghe, R.S., N. Chileshe, and R. Rameezdeen. 2019. "Information-based quality management in reverse logistics supply chain.” Benchmarking: An International Journal 
26 (7): 2146-2187.

848 Jose, A., and P. Shanmugam. 2019. "Supply chain issues in SME food sector: a systematic review." Journal of Advances in Management Research 17 (1):19-65

850

851

852

853

854

855

856

857

858

859

860

861

862

863

864

865

866

867

868

869

870

871

872

873

874

875

876

877

Joshi, R., D.K. Banwet, and R. Shankar. 2009. "Indian cold chain: modeling the inhibitors." British Food Journal 111(11): 1260-1283.

Kamalahmadi, M., and M. M. Parast. 2016. "A Review of the Literature on the Principles of Enterprise and Supply Chain Resilience: Major Findings and Directions for Future Research.” International Journal of Production Economics 171: 116-133.

Kamble, S.S., A. Gunasekaran, and R. Sharma.2018b.“Analysis of the driving and dependence power of barriers to adopt industry 4.0 in Indian manufacturing industry." Computers in Industry 101: 107-119.

Kapse, C.P., A. Kumar, M.K. Dash, E. Zavadskas, and S. Luthra. 2017. "Developing textile entrepreneurial inclination model by integrating experts mining and ISM-MICMAC.” International Journal of Production Research 56 (14): 1-20.

Kauppi, K., and C. Hannibal, 2017. "Institutional pressures and sustainability assessment in supply chains. Supply Chain Management: An International Journal 22: 458-472.

Kinra, A., D. Ivanov, A. Das, and A. Dolgui. 2019. "Ripple effect quantification by supply risk exposure assessment." International Journal of Production Research, forthcoming, https://doi.org/10.1080/00207543.2019.1675919

Kirkire, M., and S. Rane. 2017. "Evaluation of success factors for medical device development using grey DEMATEL approach.” Journal of Modelling in Management 12(2): 204-223.

Krishnan, R., R. Agarwal, C. Bajada, and K. Arshinder. 2020. "Redesigning a food supply chain for environmental sustainability-An analysis of resource use and recovery." Journal of Cleaner Production 242: 118374.

Li, D., X. Wang, H.K. Chan, and R. Manzini. 2014. "Sustainable food supply chain management.” International Journal of Production Economics 152:1-8.

Li, Y., and C.W. Zobel. 2020. "Exploring supply chain network resilience in the presence of the ripple effect." International Journal of Production Economics, 228: 107693.

Lin, R.J. 2013.“Using fuzzy DEMATEL to evaluate the green supply chain management practices."Journal of Cleaner Production 40: 32-39.

Linton, T., and B. Vakil. 2020. Coronavirus is proving we need more resilient supply chains. 
Harvard Business Review, March 5, 2020. Accessed March 10, 2020.https://hbr.

Luthra, S., S.K. Mangla, L. Xu, and A. Diabat. 2016. "Using AHP to evaluate barriers in adopting sustainable consumption and production initiatives in a supply chain." International Journal of Production Economics 181: 342-349.

Luvisi, A. 2016. "Electronic identification technology for agriculture, plant, and food: A review." Agronomy for Sustainable Development 36 (13): 1-14.

Manavalan, E., and K. Jayakrishna. 2019. "A review of internet of things (IoT) embedded sustainable supply chain for industry 4.0 requirements." Computers \& Industrial Engineering 127: 925-953.

Mangla, S.K., K. Govindan, and S. Luthra. 2017. "Prioritising the barriers to achieve sustainable consumption and production trends in supply chains using fuzzy Analytical Hierarchy Process.” Journal of Cleaner Production 151:509-525.

Mangla, S.K., S. Luthra, N. Rich, D. Kumar, N.P. Rana, and Y.K. Dwivedi. 2018. "Enablers to implement sustainable initiatives in agro based-food supply chains." International Journal of Production Economics 203: 379-393.

Miemczyk, J., T.E. Johnsen, and M. Macquet. 2012. "Sustainable purchasing and supply management: a structured literature review of definitions and measures at the dyad, chain and network levels." Supply Chain Management: An International Journal 17 (5): 478496.

Misangyi, V.F., T. Greckhamer, S. Furnari, P.C. Fiss, D. Crilly, and R. Aguilera. 2016. "Embracing causal complexity: the emergence of a neo-configurationally perspective." Journal of Management 43(1): 255-282.

Mishra, S., S.P. Singh, J. Johansen, Y. Cheng, and S. Farooq. 2018. "Evaluating indicators for international manufacturing network under circular economy." Management Decision 57 (4): 811-839.

Moazzam, M., P. Akhtar, E. Garnevska, and N. E. Marr. 2018. "Measuring agri-food supply chain performance and risk through a new analytical framework: A case study of New Zealand dairy.” Production Planning \& Control 29 (15): 1258-1274.

Naik, G., and D.N. Suresh. 2018. "Challenges of creating sustainable agri-retail supply chains." IIMB Management Review 30 (3): 270-282.

Nakandala, D., P. Samaranayake, H. Lau, and K. Ramanathan. 2017. "Modelling information 
flow and sharing matrix for fresh food supply chains." Business Process Management Journal 23 (1): 108-129

Opricovic, S., and G.H. Tzeng. 2003. "Defuzzification within a multi criteria decision model." International Journal of Uncertainty' Fuzziness and Knowledge-Based Systems 11(5): 635-652.

Overstreet, R.E., J. B. Hanna, T.A. Byrd, C.G. Gegielski, and B.T. Hazen. 2013. "Leadership style and organizational innovativeness drive motor carriers toward sustained performance." International Journal of Logistics Management 24 (2): 247-270

Papadopoulos, T., A. Gunasekaran, R. Dubey, N. Altay, S. J. Childe, and S.F. Wamba. 2017. "The role of big data in explaining disaster resilience in supply chains for sustainability." Journal of Cleaner Production 142 (2): 1108-1118.

Raja Ambedkar, A., P. Murugesan, and N. Thamaraiselvan. 2018. "Modeling brand resonance score (BRS) - an application in financial services." Journal of Modeling in Management 13(1): 119-136.

Saberi, S., M. Kouhizadeh, J. Sarkis, and L. Shen. 2019. "Blockchain technology and its relationships to sustainable supply chain management." International Journal of Production Research 57 (7): 2117-2135.

Schanes, K., K. Dobernig, and B.Gozet. 2018. "Food waste matters-a systematic review of household food waste practices and their policy implications." Journal of Cleaner Production 182: 978-991.

Seçme, N., A. Bayrakdaroglu, and C. Kahraman. 2009. "Fuzzy performance evaluation in Turkish banking sector using analytic hierarchy process and TOPSIS." Expert Systems with Applications 36 (9): 11699-11709.

Sharma, N., and P. Vrat. 2018. "Impact of various factors on stock-induced food waste in Indian weddings: a system dynamics approach." Journal of Advances in Management Research 15 (1): 37-57.

Shen, L., X. Song, S. Wu, Y. Liao, and X. Zhang. 2016. "Interpretive structural modeling based factor analysis on the implementation of emission trading system in the Chinese building sector." Journal of Cleaner Production 127: 214-227.

Shih, C. W., and C. H. Wang. 2016. "Integrating wireless sensor networks with statistical quality control to develop a cold chain system in food industries." Computer Standards \& 
Interfaces 45: 62-78.

Shukla, S., R. Shankar, and S.P. Singh. 2014. "Food safety regulatory model in India." Food Control 37: 401-413.

Singh, R.K., S. Luthra, S.K. Mangla, and S. Uniyal. 2019. "Applications of information and communication technology for sustainable growth of SMEs in India food industry." Resources, Conservation and Recycling 147: 10-18.

Talavera, J.M., L.E. Tobón, J.A. Gómez, M.A. Culman, J.M. Aranda, D.T. Parra, L.A. Quiroz, A. Hoyos, and L.E. Garreta. 2017. "Review of IoT applications in agro-industrial and environmental fields." Computers and Electronics in Agriculture 142 (Part A): 283-297.

Tan, Y., L. Shen, C. Langston, and Y. Liu. 2010. "Construction project selection using fuzzy TOPSIS approach." Journal of Modeling in Management 5 (3): 302-315.

Tzeng, G.H., C.H. Chiang, C.W. Li. 2007. "Evaluating intertwined effects in e-learning programs: A novel hybrid MCDM model based on factor analysis and DEMATEL." Expert System with Application 32 (4): 1028-1044.

Validi, S., A. Bhattacharya, and P.J. Byrne. 2014. "A case analysis of a sustainable food supply chain distribution system - a multi-objective approach." International Journal of Production Economics 152: 71-87.

Vanderroost, M., P. Ragaert, J. Verwaeren, B. DeMeulenaer, B. De Baets, and F. Devlieghere. 2017. "The digitization of a food package's life cycle: existing and emerging computer systems in the logistics and post-logistics phase." Computers in Industry 87: 15-30.

Warfield, J.N. 1974. "Developing interconnection matrices in structural modeling." IEEE Transactions on Systems, Man, and Cybernetics 4 (1): 81-87.

Wilhelm, M., C. Blome, E. Wieck, and C.Y. Xiao. 2016b. "Implementing sustainability in multi-tier supply chains: strategies and contingencies in managing sub-suppliers." International Journal of Production Economics 182: 196-212.

Wolfert, S., L. Ge, C.Verdouw, and M. J. Bogaardt. 2017. "Big data in smart farming-a review." Agricultural Systems 153: 69-80.

Wu, W.W. 2008."Choosing knowledge management strategies by using a combined ANP and DEMATEL approach.” Expert System with Application 35 (3): 828-835.

Xu, S., X. Zhang, L. Feng, W.Yang. 2020. "Disruption risks in supply chain management: a literature review based on bibliometric analysis." International Journal of Production 
$971 \quad$ Research 58 (11): 3508-3526.

972 Zadeh, L.A. 1965. "Fuzzy sets.” Information and Control 8 (3): 338-353.

973 Zhu, Q., Y. Feng, S.B. Choi. 2017. "The role of customer relational governance in 974 environmental and economic performance improvement through green supply chain 975 management." Journal of Cleaner Production 155: 46-53.

976

977

978

979

980

981

982

983

984

985

986

987

988

989

990

991

992

993

994

995

996

997

998 


\section{$\underline{\text { Appendices }}$}

1000

1001

1002

1003

1004

1005

1006

1007

1008

1009

1010

1011

1012

1013

1014

1015

1016

1017

1018

1019

1020

1021

1022

1023

1024

1025

1026

1027

1028

\section{$\underline{\text { Appendix-A }}$}

Sample Questionnaire

\section{Dear Respondents}

Greetings...

This research has been done for identification and analysis of factors of an IoT based AFSC sustainability in any disruption of SC caused by natural epidemics (COVID 19). For developing an IoT based sustainable food security system. This sample is also a part of the present research work. Your response to questions will not be share to any organisation. Your response may guide to analyse the identified factors provided by literature. We would be grateful and highly obliged if you response to some of the questions in section I, section II and filling up the response sheet in Section III. All the personal information will not be shared to anyone.

Sincerely

Authors

\section{Section I}

\section{General Information about experts}

Please click only one option

1. What is your basic qualification level?

○ Graduate

○ Post Graduate

○ Doctorate

- Any other, please specify

\section{What is your work experience?}

- Less than 10 Years

○ $10-15$ Years

○ 15-20 Years

- Greater than 20 Years 
3. What is the area of your expertise related to IoT based food security system?

1031

○ Logistics department

1032

○ Food and worker safety

1033

○ Government Regulatory bodies

1034

○ Environmental and disaster management

1035

- Agri food procurement strategies

1036

○ Any other, please specify...........

1037

1038

1039

1040

1041

1042

1043

4. What is the designation of the selected decision makers in particular organisation?

○ Manager

○ Supervisor

○ Chief Executive Officer

- R\&D team member

1044

1045

1046

1047

1048

1049

1050

1051

1052

1053

○ Any other, please specify..........

1054

1055

1056

1057

1058

Please click only one option

1. What is the area of the cultivated farmlands attached to your firm?

\section{General Information about the firm}

$\circ$ Under 5 acres

○ 5 to 10 acres

○ 10 to 15 acres

○ Over 15 acres

2. What is your firm sales volume?

1059

○ Under 30 million

○ 30 to 40 million

○ 40 to 50 million

○ Over 50 million 
3. How many employers have been worked in your firm?

1062

1063

1064

1065

○ Under 100

1066

4. What is the experience of your firm in implementing IoT related technology?

1069

1070

1071

○ 100 to 500

○ 500 to 1000

O Over 1000

1072

1073

1074

○ Less than 6 months

○ 6 to 12 months

○ More than a year

- Any other, please specify.

1075

1076

1077

1078

1079

1080

1081

1082

\section{Section III}

Decision maker's preference to the identified factors

\section{Response sheet: Study the interaction among identified factors for ISM approach}

ISM approach has been employed to study the interaction among identified factors. According to procedure of ISM, we need your judgment in development of SSIM. Following four denotations used for correlating among two variable ' $i$ ' and ' $j$ '.

$\mathrm{V}: \mathrm{i}$ drive the $\mathrm{j}$.

A: $\mathrm{j}$ drives the $\mathrm{i}$.

$\mathrm{X}$ : $\mathrm{i}$ and $\mathrm{j}$ each other.

$\mathrm{O}: \mathrm{i}$ and $\mathrm{j}$ are unrelated.

Please give your response in below table for SSIM development of enablers.

\begin{tabular}{|c|c|c|c|c|c|c|c|c|c|c|c|c|c|c|c|}
\hline $\begin{array}{l}\text { S. } \\
\text { No. }\end{array}$ & $\begin{array}{c}\text { Factors for IoT based sustainable food } \\
\text { security system }\end{array}$ & 1 & 2 & 3 & 4 & 5 & 6 & 7 & 8 & 9 & 10 & 11 & 12 & 13 & 14 \\
\hline 1 & E-governance and policy(C1) & & & & & & & & & & & & & & \\
\hline 2 & Education and training $(\mathrm{C} 2)$ & & & & & & & & & & & & & & \\
\hline 3 & Top management support (C3) & & & & & & & & & & & & & & \\
\hline 4 & IoT based infrastructure (C4) & & & & & & & & & & & & & & \\
\hline
\end{tabular}




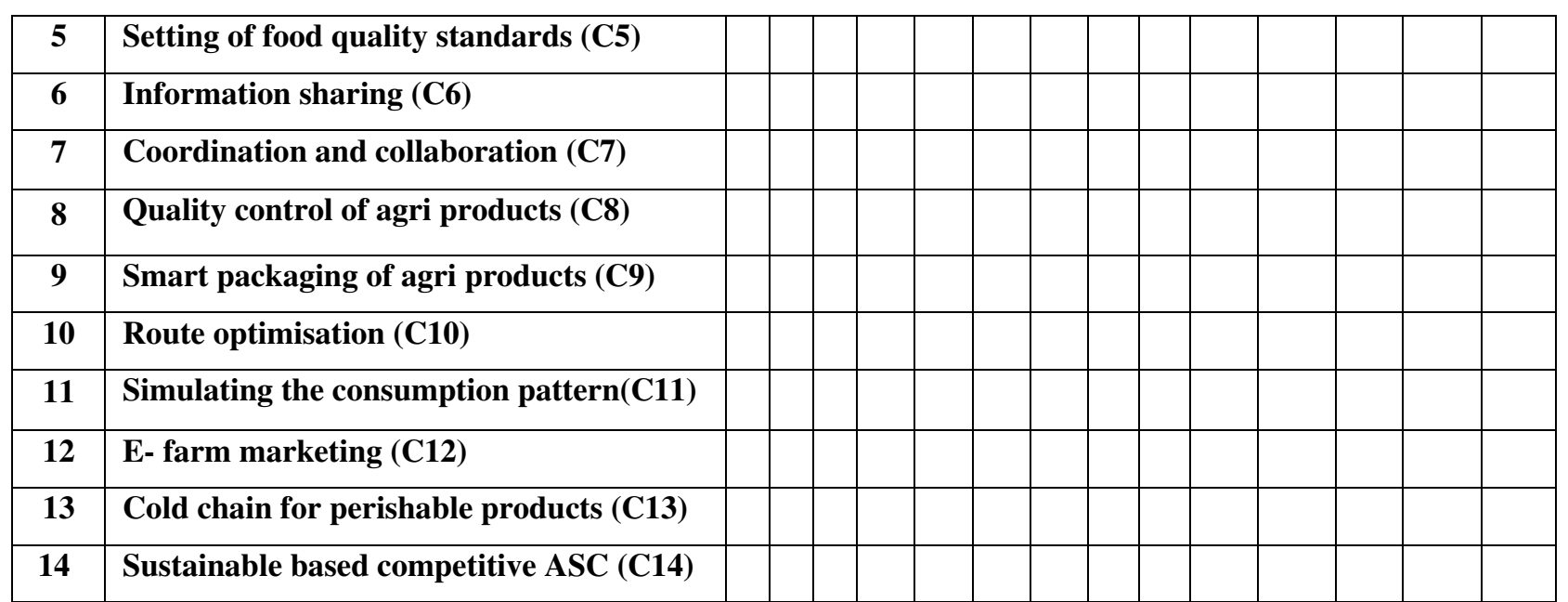

\section{Response sheet: Analysing the identified factors to understand their causal relations}

Please rate the following enablers on 5 point Likert scale for constructing a direct relational matrix. For measuring the extent of relation established between two factors a TFN (Triangular Fuzzy Number) scale has followed i.e. $(0,0.1,0.3)$ for (no relation) for , $(0.1,0.3,0.5)$ (very low relation), $(0.3,0.5,0.7)$ (low relation), $(0.5,0.7,0.9)$ (high relation) and $(0.7,0.9,1)$ (very high relation) respectively. Further, based on your expertise, you may add/delete any other variable.

\begin{tabular}{|c|c|c|c|c|c|c|c|c|c|c|c|c|c|c|c|}
\hline $\begin{array}{l}\text { S. } \\
\text { No. }\end{array}$ & $\begin{array}{c}\text { Factors for IoT based sustainable food } \\
\text { security system }\end{array}$ & $\mathbf{1}$ & 2 & 3 & 4 & 5 & 6 & 7 & 8 & 9 & 10 & 11 & 12 & 13 & 14 \\
\hline 1 & E-Governance and policy $(\mathrm{C} 1)$ & & & & & & & & & & & & & & \\
\hline 2 & Education and training (C2) & & & & & & & & & & & & & & \\
\hline 3 & Top management support (C3) & & & & & & & & & & & & & & \\
\hline 4 & IoT based infrastructure (C4) & & & & & & & & & & & & & & \\
\hline 5 & Setting of food quality standards (C5) & & & & & & & & & & & & & & \\
\hline 6 & Information sharing (C6) & & & & & & & & & & & & & & \\
\hline 7 & Coordination and collaboration (C7) & & & & & & & & & & & & & & \\
\hline 8 & Quality control of agri products $(\mathrm{C8})$ & & & & & & & & & & & & & & \\
\hline 9 & Smart packaging of agri products (C9) & & & & & & & & & & & & & & \\
\hline 10 & Route optimisation (C10) & & & & & & & & & & & & & & \\
\hline 11 & Simulating the consumption pattern $(\mathbf{C 1 1})$ & & & & & & & & & & & & & & \\
\hline 12 & E- Farm marketing (C12) & & & & & & & & & & & & & & \\
\hline 13 & Cold chain for perishable products (C13) & & & & & & & & & & & & & & \\
\hline
\end{tabular}


1091

\begin{tabular}{|l|l|}
\hline 14 & Sustainable based competitive ASC (C14)
\end{tabular}

$1092 \quad$ Name of Expert .........................

1093 Authority ...................................

1094 Department

1095 Email..

1096 Date and place.

1097

1098

Thank you very much for giving valuable response

1099 If any other suggestion, specify in box

1100
1101
1102

1103

1104

1105

1106

1107

1108

1109

1110

1111

1112

1113

1114

1115

1116

1117

1118

1119 
1122 Table B1: Initial SSIM for enablers based on experts

\begin{tabular}{|c|c|c|c|c|c|c|c|c|c|c|c|c|c|c|}
\hline & C1 & C2 & C3 & C4 & C5 & C6 & C7 & C8 & C9 & C10 & C11 & C12 & C13 & C14 \\
\hline C1 & - & O & V & V & V & V & V & V & V & V & V & O & V & V \\
\hline C2 & & - & O & V & V & X & V & V & V & V & V & V & V & V \\
\hline C3 & & & - & V & V & V & V & V & O & O & O & O & O & V \\
\hline C4 & & & & - & O & X & V & O & V & O & O & V & V & V \\
\hline C5 & & & & - & V & V & O & V & V & O & O & O & V \\
\hline C6 & & & & & - & O & O & V & V & V & V & O & V \\
\hline C7 & & & & & & & - & A & V & V & V & V & X & V \\
\hline C8 & & & & & & & - & O & V & V & V & A & O \\
\hline C9 & & & & & & & & - & V & X & A & A & V \\
\hline C10 & & & & & & & & & - & O & O & O & V \\
\hline C11 & & & & & & & & & & - & O & O & O \\
\hline C12 & & & & & & & & & & & & - & V & O \\
\hline C13 & & & & & & & & & & & & & - & O \\
\hline C14 & & & & & & & & & & & & & & - \\
\hline
\end{tabular}

1124 Table B2: Normalised direct relational matrix based on aggregate rating of experts

\begin{tabular}{|c|c|c|c|c|c|c|c|c|c|c|c|c|c|c|}
\hline & C1 & C2 & C3 & C4 & C5 & C6 & C7 & C8 & C9 & C10 & C11 & $\mathrm{C} 12$ & C13 & C14 \\
\hline C1 & 0.0137 & 0.0798 & 0.0674 & 0.0464 & 0.0755 & 0.0591 & 0.0920 & 0.0796 & 0.0758 & 0.0798 & 0.0836 & 0.0591 & 0.0547 & 0.0879 \\
\hline C2 & 0.0507 & 0.0137 & 0.0836 & 0.0631 & 0.0960 & 0.0630 & 0.0672 & 0.0549 & 0.0342 & 0.0960 & 0.0839 & 0.0960 & 0.0507 & 0.0879 \\
\hline C3 & 0.0672 & 0.0960 & 0.0137 & 0.0588 & 0.0920 & 0.0562 & 0.0836 & 0.0796 & 0.0712 & 0.0631 & 0.0836 & 0.0879 & 0.0562 & 0.0920 \\
\hline $\mathrm{C4}$ & 0.0340 & 0.0712 & 0.0547 & 0.0137 & 0.0713 & 0.0758 & 0.0879 & 0.0672 & 0.0712 & 0.0755 & 0.0302 & 0.0549 & 0.0758 & 0.0960 \\
\hline C5 & 0.0507 & 0.0960 & 0.0588 & 0.0588 & 0.0137 & 0.0674 & 0.0712 & 0.0591 & 0.0960 & 0.0836 & 0.0712 & 0.0137 & 0.0591 & 0.0960 \\
\hline C6 & 0.0549 & 0.0712 & 0.0506 & 0.0549 & 0.0591 & 0.0137 & 0.0630 & 0.0591 & 0.0836 & 0.0672 & 0.0549 & 0.0758 & 0.0137 & 0.0796 \\
\hline C7 & 0.0591 & 0.0588 & 0.0588 & 0.0631 & 0.0630 & 0.0423 & 0.0137 & 0.0758 & 0.0588 & 0.0712 & 0.0672 & 0.0672 & 0.0423 & 0.0137 \\
\hline C8 & 0.0178 & 0.0592 & 0.0716 & 0.0547 & 0.0674 & 0.0507 & 0.0672 & 0.0137 & 0.0758 & 0.0758 & 0.0712 & 0.0507 & 0.0340 & 0.0839 \\
\hline C9 & 0.0589 & 0.0220 & 0.0507 & 0.0547 & 0.0920 & 0.0588 & 0.0712 & 0.0631 & 0.0137 & 0.0836 & 0.0879 & 0.0960 & 0.0465 & 0.0839 \\
\hline $\mathrm{C10}$ & 0.0589 & 0.0589 & 0.0259 & 0.0796 & 0.0960 & 0.0549 & 0.0575 & 0.0796 & 0.0836 & 0.0137 & 0.0588 & 0.0839 & 0.0438 & 0.0960 \\
\hline C11 & 0.0547 & 0.0547 & 0.0547 & 0.0342 & 0.0549 & 0.0716 & 0.0507 & 0.0713 & 0.0836 & 0.0879 & 0.0137 & 0.0549 & 0.0758 & 0.0960 \\
\hline $\mathrm{C} 12$ & 0.0591 & 0.0879 & 0.0796 & 0.0672 & 0.0260 & 0.0634 & 0.0423 & 0.0673 & 0.0960 & 0.0960 & 0.0836 & 0.0137 & 0.0507 & 0.0960 \\
\hline $\mathrm{C13}$ & 0.0547 & 0.0423 & 0.0588 & 0.0465 & 0.0549 & 0.0218 & 0.0340 & 0.0423 & 0.0712 & 0.0878 & 0.0713 & 0.0758 & 0.0137 & 0.0713 \\
\hline C14 & 0.0674 & 0.0672 & 0.0464 & 0.0588 & 0.0712 & 0.0589 & 0.0340 & 0.0465 & 0.0712 & 0.0960 & 0.0836 & 0.0713 & 0.0423 & 0.0137 \\
\hline
\end{tabular}




\section{Declarations}

1128

1129 Ethics approval and consent to participate: All authors follow the ethics in the research and provide

1130 consent to participate in the research.

1131 Consent for publication: All authors provide consent for publication.

1132 Availability of data and material: All the data has been provided in manuscript

1133 Competing interests: The authors declare that they have no known competing financial interests or 1134 personal relationships that could have appeared to influence the work reported in this paper.

1135 Funding: No

1136 Authors' contributions: Sanjeev Kumar: Ideas, Conceptualization, Writing-Original draft preparation, Data collection and 1137 curation, Methodology, Formal analysis

1138 Sunil Luthra: Ideas, Writing- Original draft preparation, Conceptualization, Formal analysis, Project administration, Critical review, 1139 Commentary and revision

1140 Dixit Garg: Data collection and curation, Formal Analysis, Supervision, Reviewing and Editing

1141 Acknowledgements: The authors would like to thank experts used in research. 
Figures

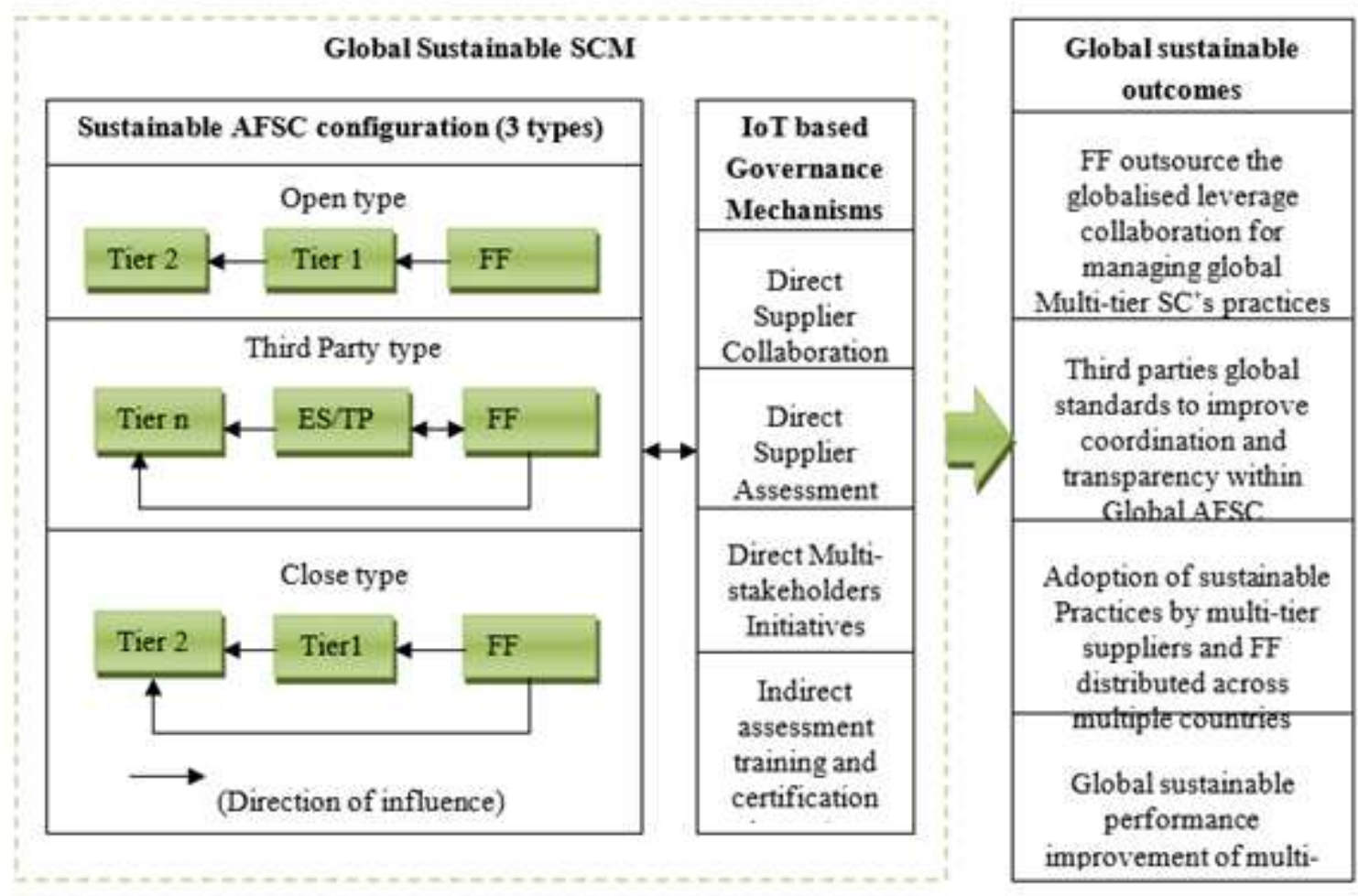

Figure 1

Research framework of Sustainable AFSC and Global AFSC 


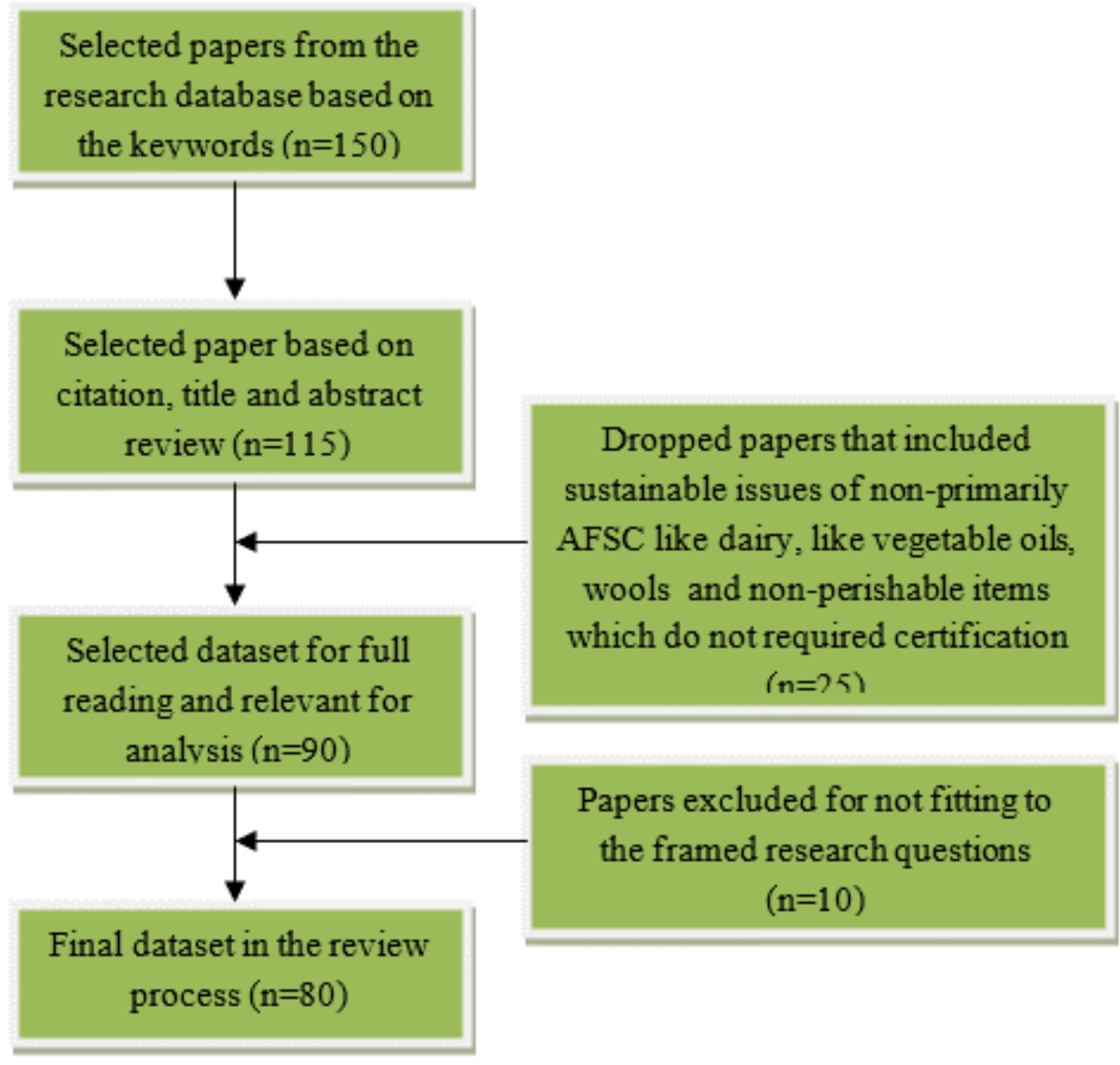

\section{Figure 2}

Article searching, selection and exclusion process 


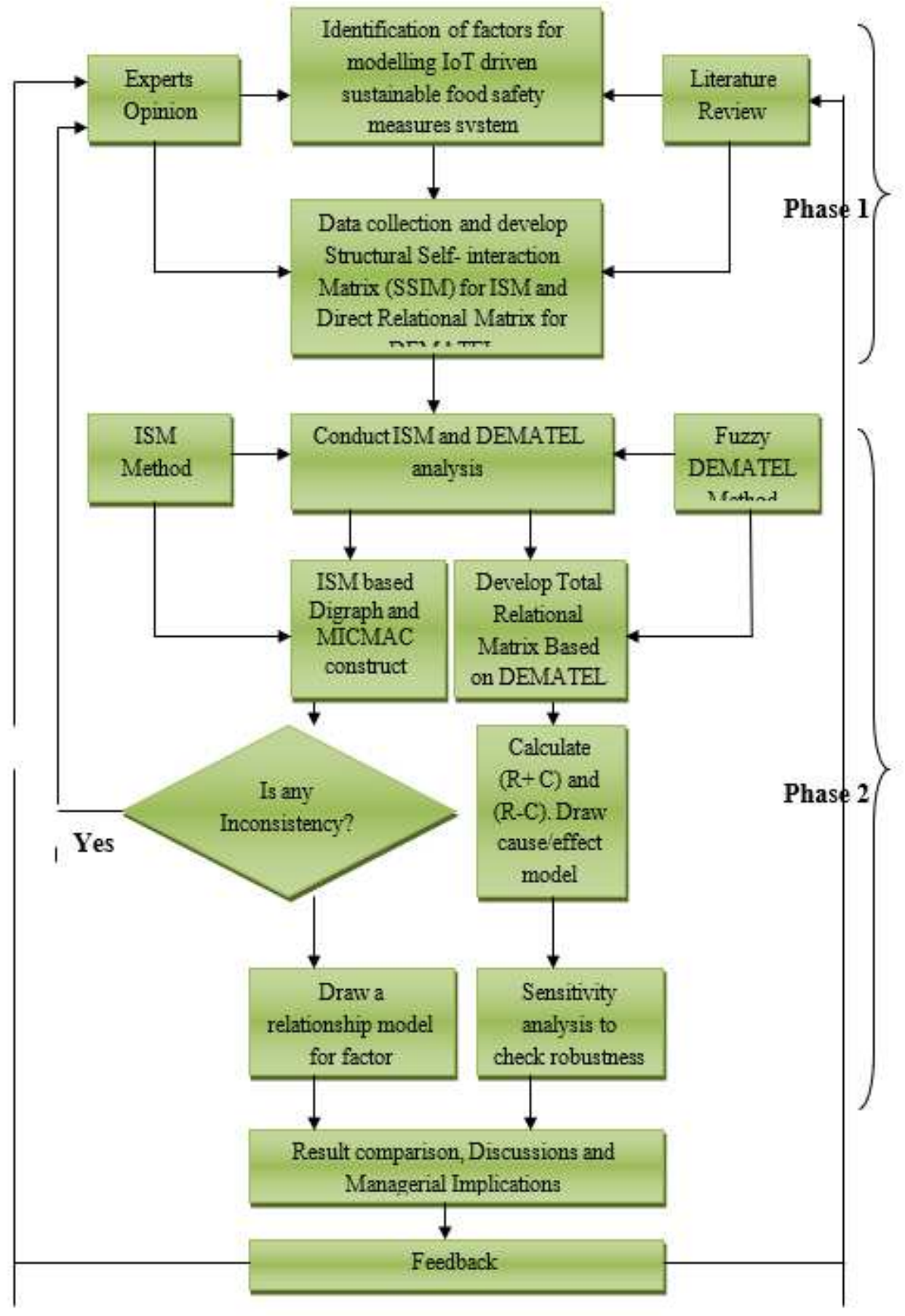

Figure 3

Framework of the proposed research 


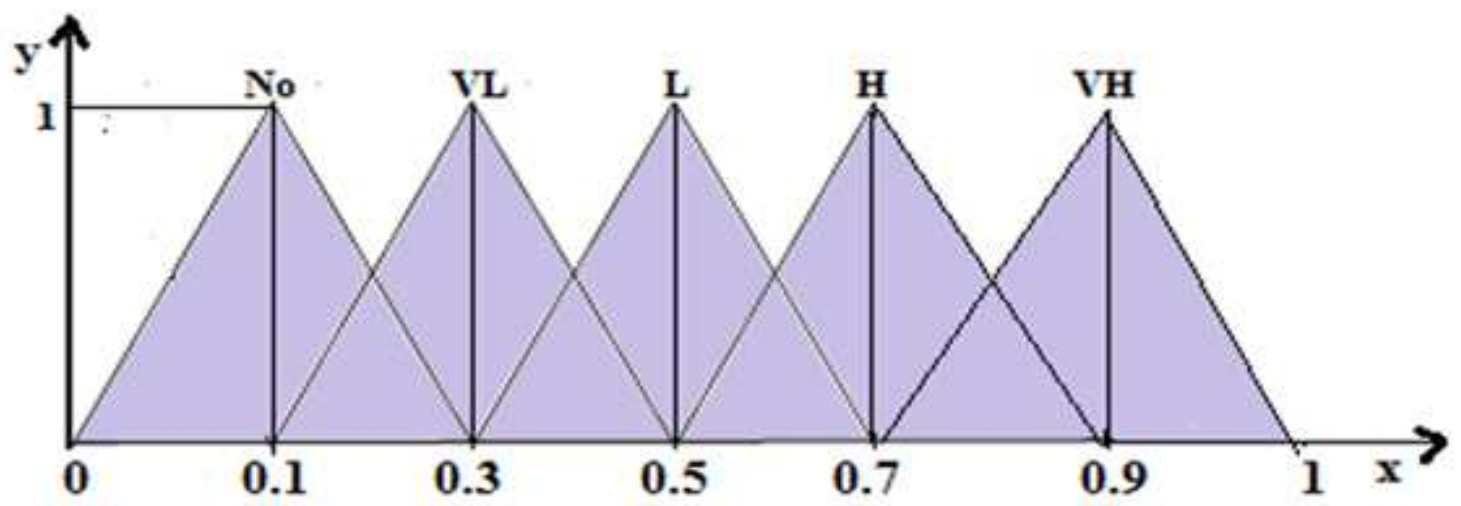

Figure 4

Triangular fuzzy numbers

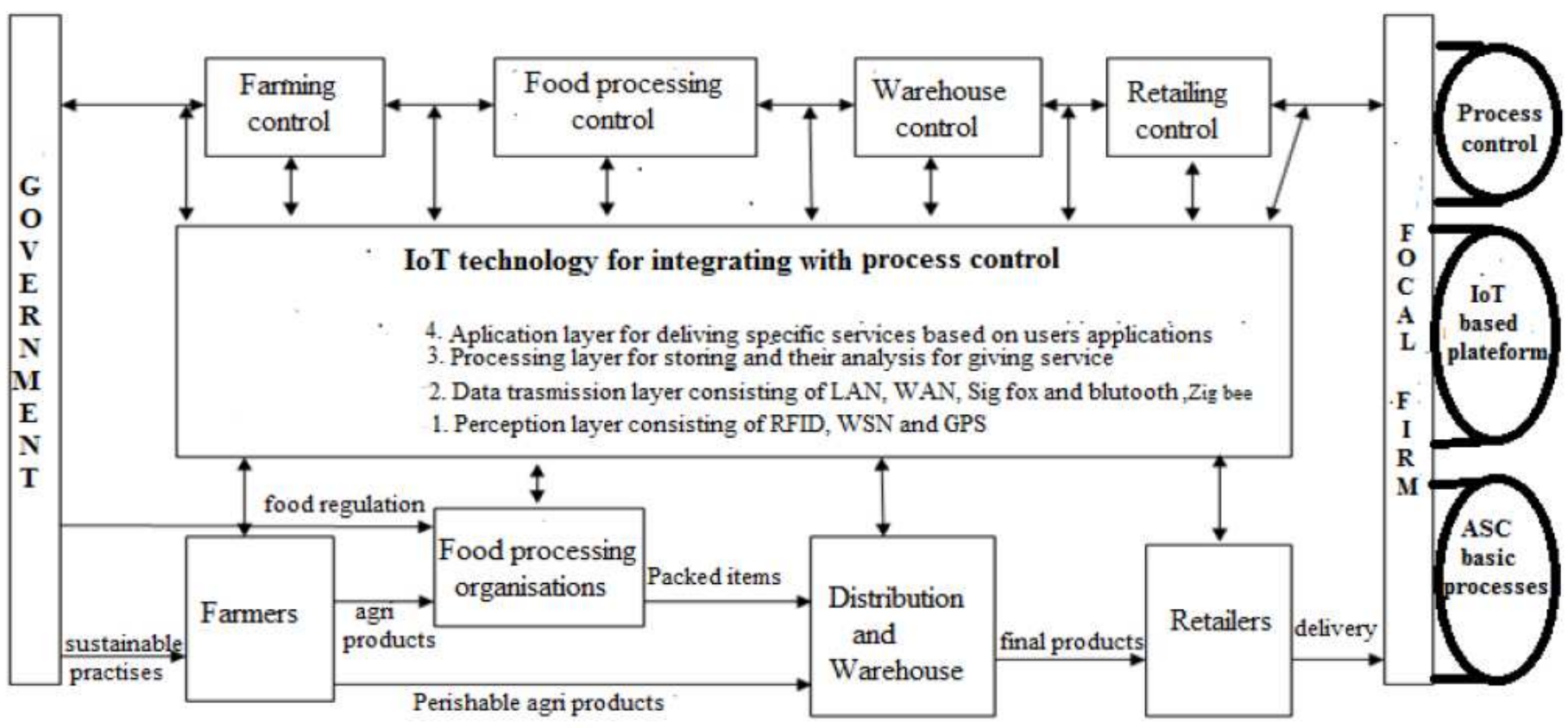

(Information flow)

(Product flow)

Figure 5

Complete framework of the proposed case study for XYZ firm 


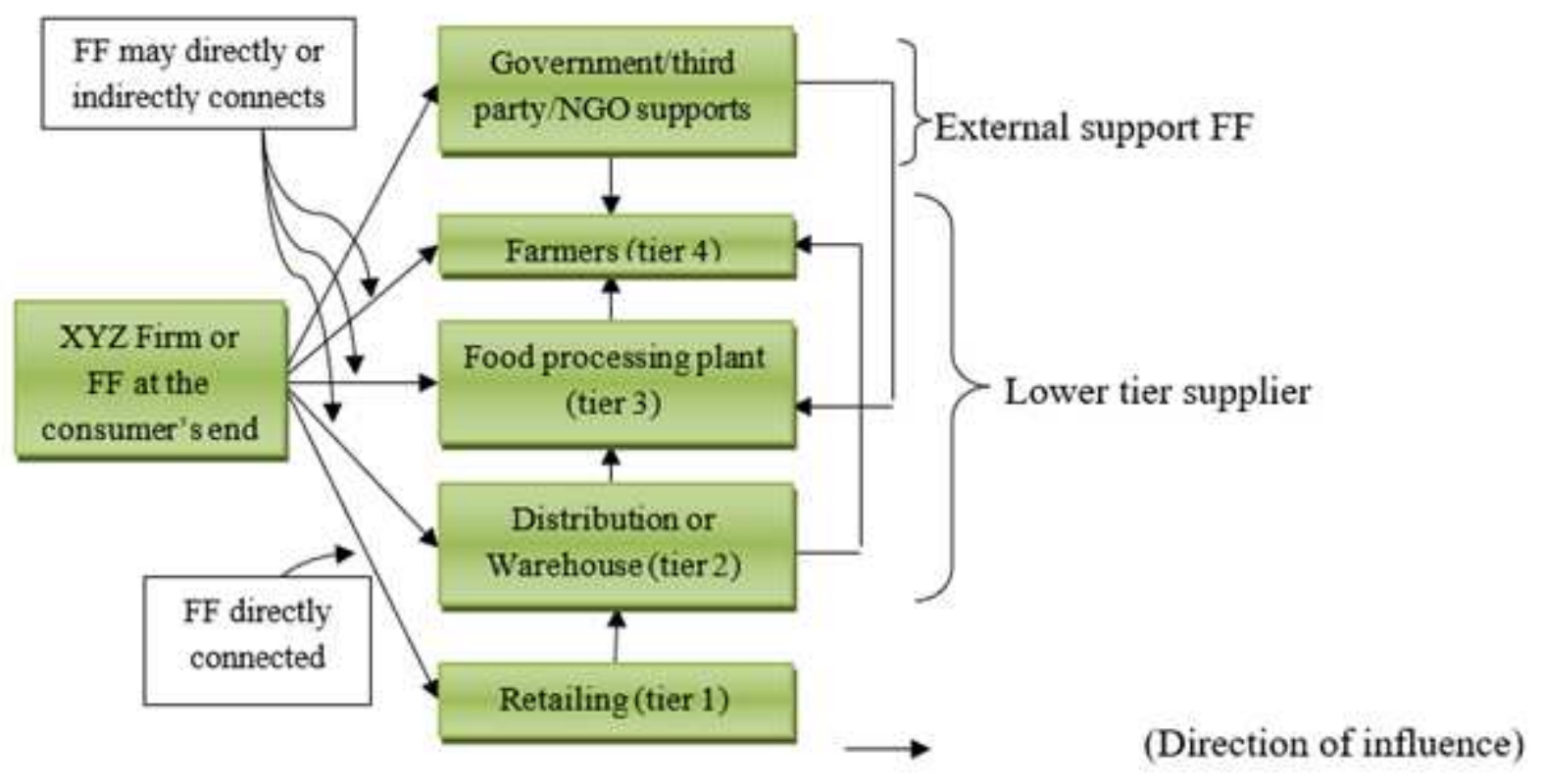

Figure 6

Multi-tier view of AFSC

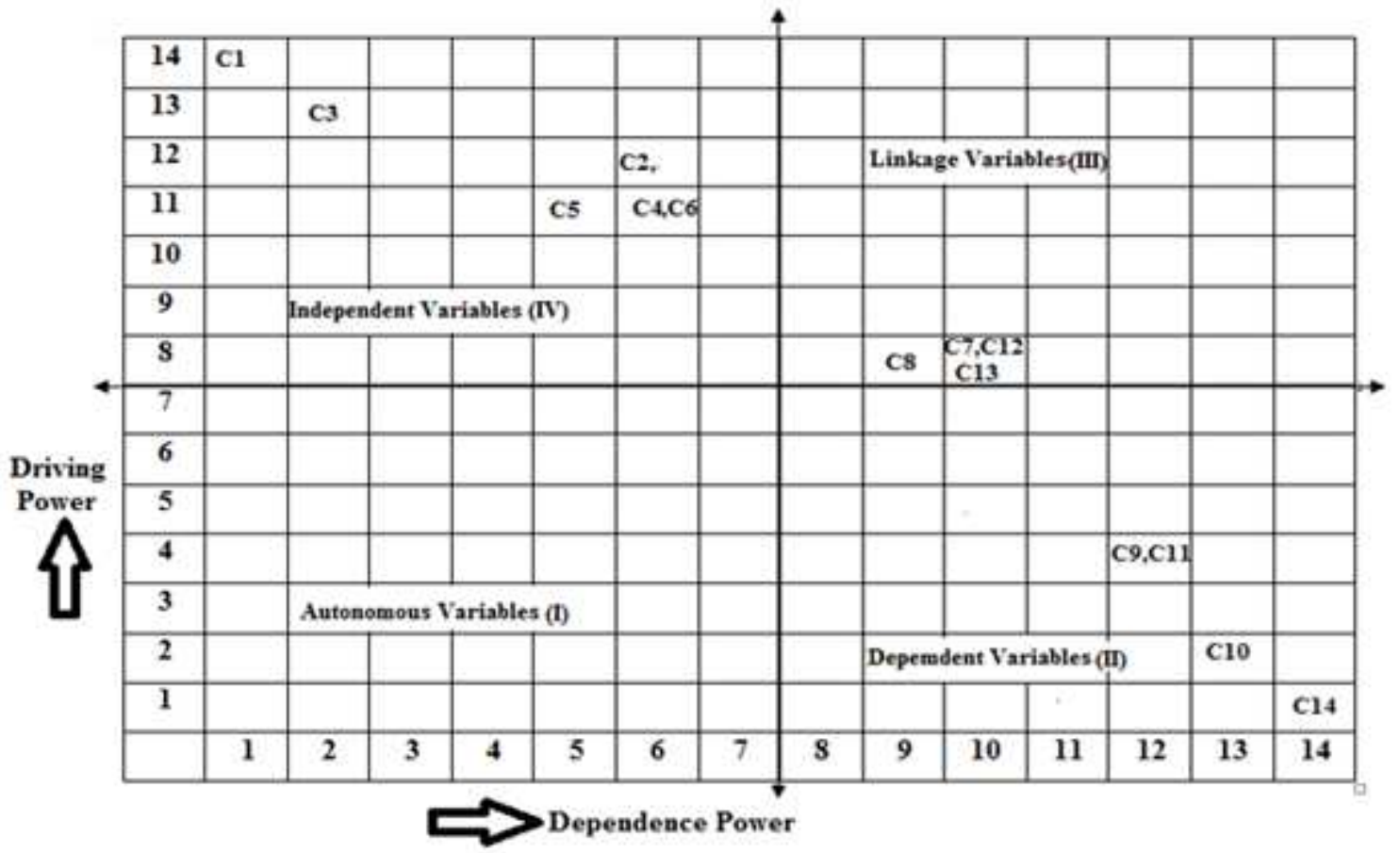

Figure 7

ISM based MICMAC analysis 


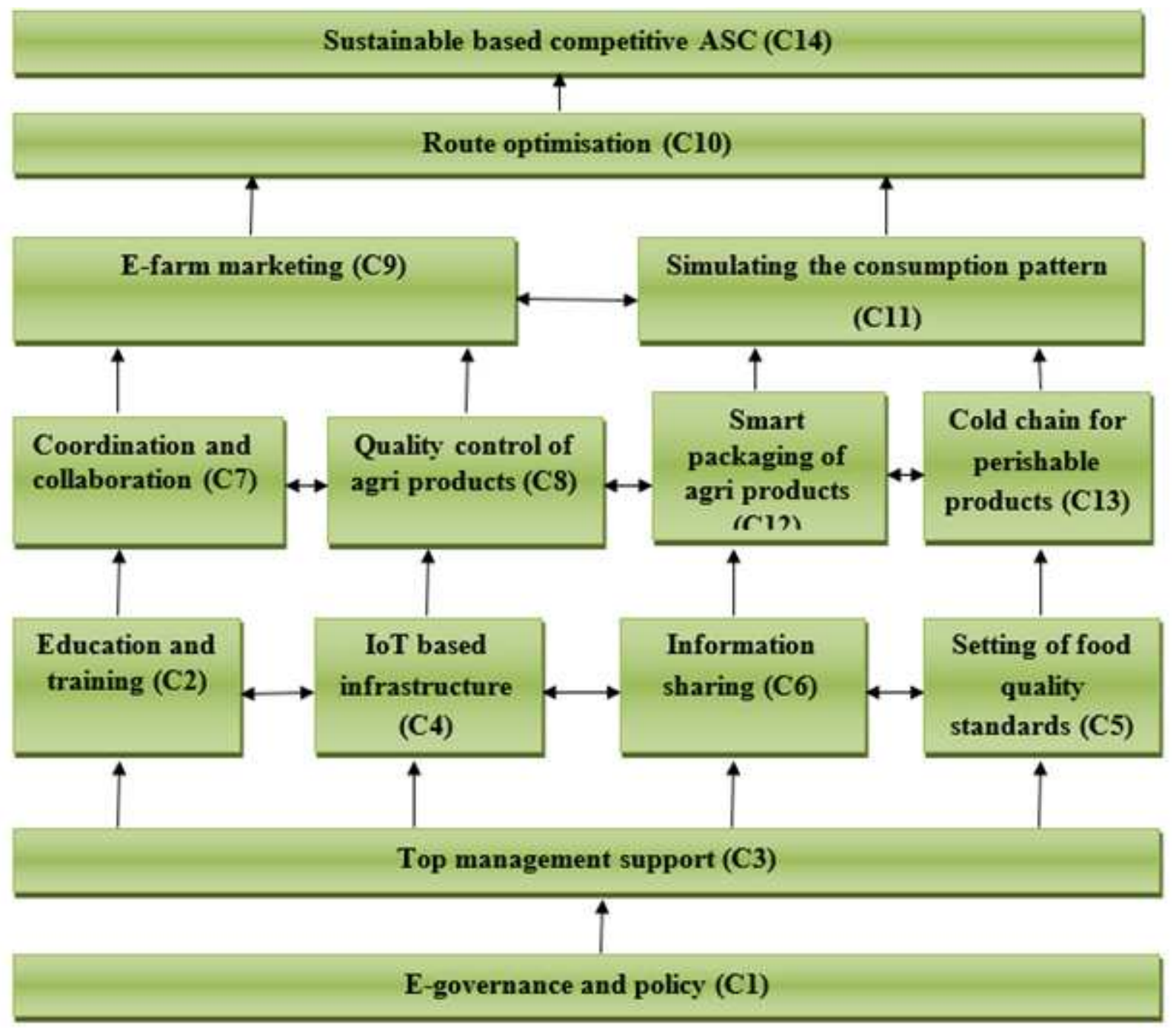

Figure 8

ISM based hierarchical structure for showing dependencies 


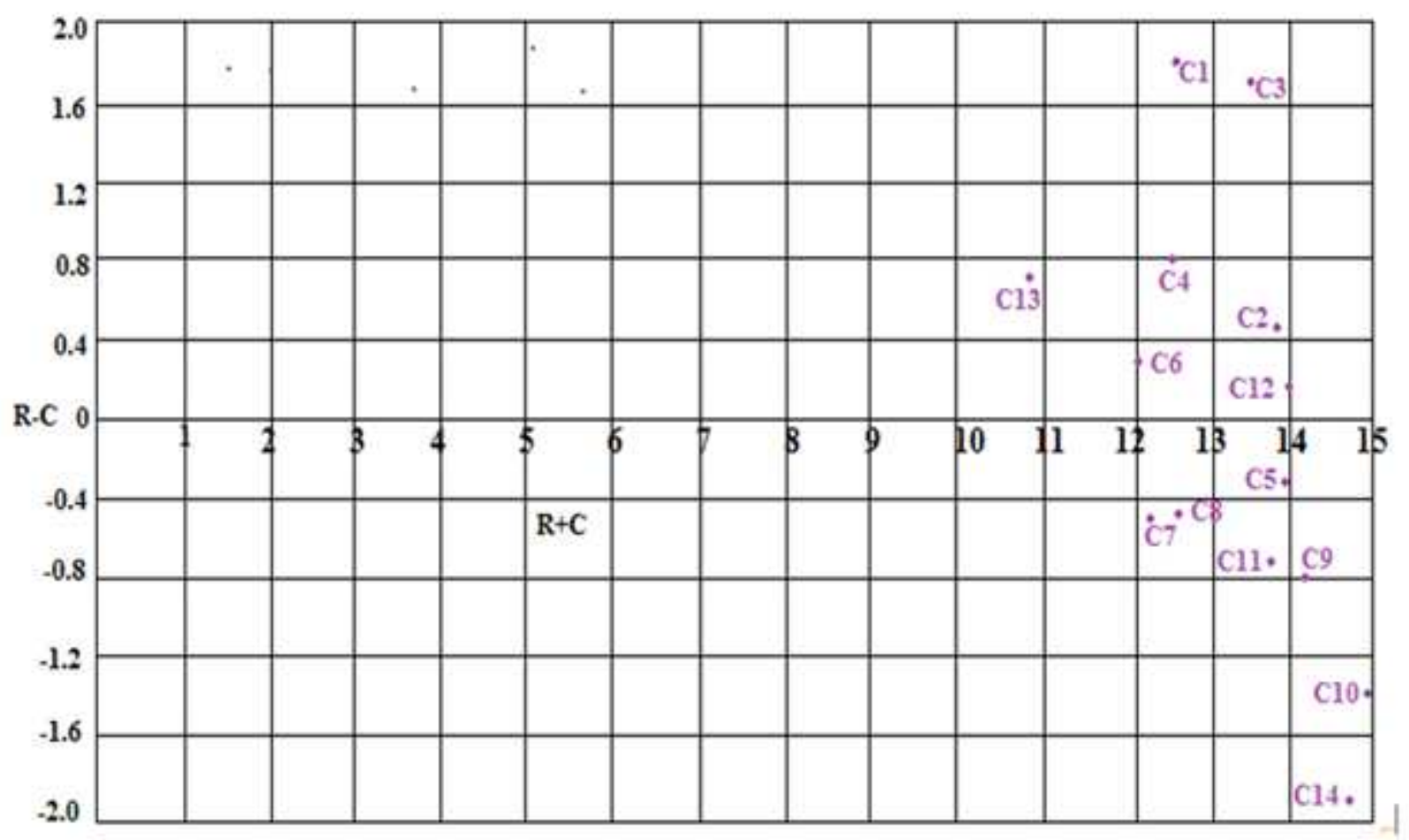

Figure 9

The cause and effect diagram of enablers

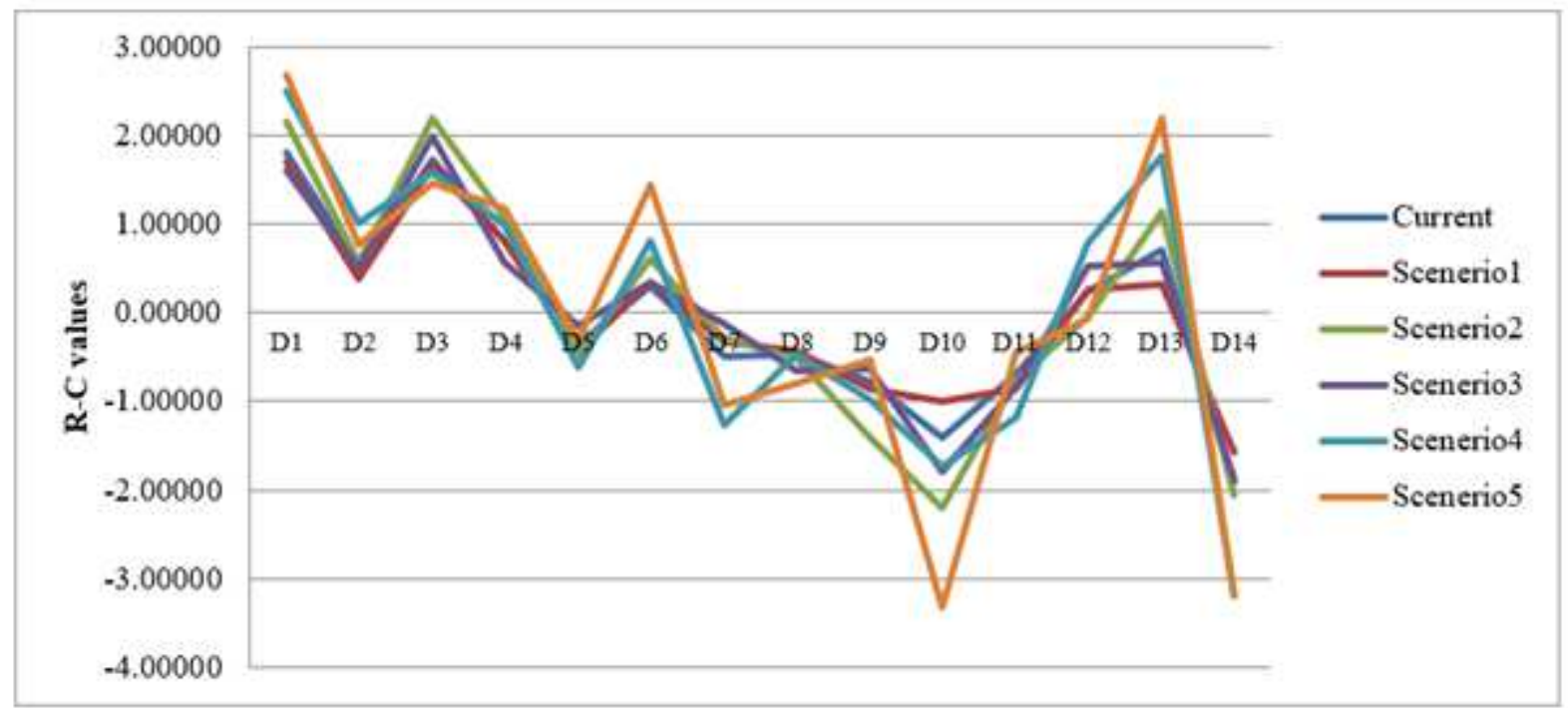

Figure 10

Sensitivity analysis of $(R-C)$ values

\section{Supplementary Files}

This is a list of supplementary files associated with this preprint. Click to download. 
- Appendices.docx 